\title{
Climatology of Total Cloudiness in the Arctic: An Intercomparison of Observations and Reanalyses
}

\author{
Alexander Chernokulsky and Igor I. Mokhov \\ A.M. Obukhov Institute of Atmospheric Physics, Russian Academy of Sciences, \\ 3 Pyzhevsky, Moscow 119017, Russia \\ Correspondence should be addressed to Alexander Chernokulsky, chern_av@ifaran.ru
}

Received 15 September 2011; Revised 25 December 2011; Accepted 10 January 2012

Academic Editor: Irina Repina

Copyright ( 12012 A. Chernokulsky and I. I. Mokhov. This is an open access article distributed under the Creative Commons Attribution License, which permits unrestricted use, distribution, and reproduction in any medium, provided the original work is properly cited.

\begin{abstract}
Total cloud fraction over the Arctic (north of $60^{\circ} \mathrm{N}$ ) has been evaluated and intercompared based on 16 Arctic cloud climatologies from different satellite and surface observations and reanalyses. The Arctic annual-mean total cloud fraction is about $0.70 \pm 0.03$ according to different observational data. It is greater over the ocean $(0.74 \pm 0.04)$ and less over land $(0.67 \pm 0.03)$. Different observations for total cloud fraction are in a better agreement in summer than in winter and over the ocean than over land. An interannual variability is higher in winter than in summer according to all observations. The Arctic total cloud fraction has a prominent annual cycle according to most of the observations. The time of its maximum concurs with the time of the sea ice extent minimum (early summer-late autumn) and vice versa (late spring). The main reason for the discrepancies among observations is the difference in the cloud-detection algorithms, especially when clouds are detected over the ice/snow surface (during the whole year) or over the regions with the presence of strong low-tropospheric temperature inversions (mostly in winter). Generally, reanalyses are not in a close agreement with satellite and surface observations of cloudiness in the Arctic.
\end{abstract}

\section{Introduction}

The Arctic is a very sensitive region to the global climate change [1-4]. As pointed out in the Intergovernmental Panel on Climate Change Fourth Assessment Report [2], surface air temperature in the Arctic increased in the beginning of the 21 st century by $1.0-1.5 \mathrm{~K}$ compared to 1970 s. This rate is approximately twice that of the entire Earth. According to the estimations with the global climate models (GCMs), the Arctic surface temperature may increase by $4-7 \mathrm{~K}$ to the end of the 21st century compared with the end of the 20th century $[1,2]$. An increase of air temperature is accompanied by changes in other climate variables $[1,4,5]$, particularly, a decrease of the Arctic sea ice extent $[1,6,7]$ and cloud cover changes [8-10].

Clouds play the key role in the Earth's climate system by regulating the radiation budget of the planet through reflecting shortwave radiation coming from the sun and redistributing longwave radiation coming from the Earth surface $[11,12]$. Clouds of different layers have different influence on the radiation budget. High- and mid-level cloudiness tend to warm the atmosphere by strengthening and greenhouse effect, and low-level cloudiness tends to cool atmosphere by the increase of the albedo. Additionally, cloud radiative forcing (the difference between radiation fluxes in clear sky and cloudy conditions, CRF) strongly depends on season and the time of day. Generally, in the extratropical latitudes, CRF is positive in winter (at night) and negative in summer (during the daytime). The regional magnitude of CRF can reach $100 \mathrm{~W} / \mathrm{m}^{2}$ [13-15]. As a whole, cloudiness has a global cooling effect [11], but in the Arctic region, clouds slightly enhance surface cooling only for a few weeks in the midsummer and have a warming effect in the rest of the year $[14,16-18]$.

The sensitivity of CRF is about $1 \mathrm{~W} / \mathrm{m}^{2}$ per $1 \%$ of cloud cover in the Arctic [18]. Thus, relatively a small percentage of changes in cloud cover or cloud properties could result in an anomalous climate forcing of several 
$\mathrm{W} / \mathrm{m}^{2}$. By using model simulations, Vavrus [19] showed that the positive cloud feedback may enhance the Arctic warming up to $40 \%$ under $\mathrm{CO}_{2}$ doubling. This result is partially corroborated by the observations [20]. Cloud amount has increased in the Arctic during spring, summer, and autumn in the last decades according to satellite $[8,9]$ and surface $[10,21]$ observations, which can be indicated on a small positive feedback. However, satellite and surface observations disagree on winter cloudiness trends. According to model simulations, cloudiness will increase in high latitudes in the 21 st century $[22,23]$.

Considering the importance of clouds in the Arctic, it is crucial to know exactly when and where clouds exist. However, the detection of clouds in the Arctic is intrinsically difficult. Clouds in the Arctic are mostly optically thin and low-lying $[10,16]$, and they have a little thermal and visible contrast with the underlying surface, which makes them hard to be observed from satellite mostly in winter [7, 24, 25]. The main obstacle to reliable surface observations in the Arctic is a very sparse network of ground-based observations especially over Greenland and over the Arctic Ocean [26]. In addition, visual observations are more reliable during daytime than during nighttime [27]. Several studies on an intercomparison of cloud climatologies indicate the polar regions as the regions with the largest discrepancies among observational data [28-33]. Similar conclusions were done for reanalyses and GCMs simulations [15, 34-39].

Major research programs such as Atmospheric Radiation Measurement program (ARM) [40], yearlong Surface Heat Budget of the Arctic (SHEBA) program, and, associated with it, First International Satellite Cloud Climatology Program (ISCCP) Regional Experiment (FIRE) [41-43] aimed to improve our knowledge about the Arctic atmosphere and climate and to help optimize satellite retrievals for the Arctic. Particularly, comparisons between data from these programs and satellite-derived or reanalyses data were performed in a number of studies (e.g., $[15,44,45])$. Additionally, satellites with active sensors like lidar on CALIPSO and ICESat $[46,47]$ and radar on CLOUDSAT and EarthCARE [48] have been launched in the recent years. Data provided with these satellites (or merged products like GeoPROF [49]) can improve our understanding of cloud vertical structure. However, these data are limited by $82^{\circ} \mathrm{N}$ and still too short (especially compared to an extremely narrow swath) for obtaining an adequate cloud climatology in the Arctic.

Here, we intercompare 16 cloud climatologies based on up-to-date satellite and surface observations and modern reanalyses in the Arctic region north of $60^{\circ} \mathrm{N}$. Description of datasets is given in the Section 2. We present the results of a comparative analysis in Section 3 and discuss these results in Section 4.

\section{Data}

In this study, we used cloud information from up-to-date satellite and surface observations and global reanalyses data. These data are described in Sections 2.1, 2.2, and 2.3, respectively. Brief information on data is given in Table 1 .

\subsection{Satellite Observations}

2.1.1. APP-x. The Advanced Very High Resolution Radiometer (AVHRR) Polar Pathfinder product (APP) was performed specially for polar regions $[50,51]$. Cloudiness is derived from the Cloud And Surface Parameter Retrieval (CASPR) system [52] based on twice-a-day measurements in 5 spectral channels (with the central wavelengths of $0.63,0.86,3.75$, 10.8 , and $12 \mu \mathrm{m}$ ) by the AVHRR sensors which are flown on-board NOAA polar-orbiting (Low Earth Orbit) satellites (LEO). The combination of spectral and temporal uniformity tests is used in cloud mask algorithm [52]. According to several studies [44, 51], APP data has a good agreement with data from the SHEBA and FIRE field experiments. The extended version of APP (APP-x) was used in this study. Data provide information on polar cloudiness from January 1982 to December 2004 at a $25 \mathrm{~km}$ spatial resolution.

2.1.2. CERES. The main aim of the Clouds and Earth's Radiant Energy System (CERES) is an examination of the role of the cloud-radiation feedbacks in the climate system [53] by providing the simultaneous retrievals of cloud properties and broadband radiative fluxes from the instruments on two LEOs, Terra and Aqua, from the Earth Observing System. Terra satellite was launched in December 1999 and has a 10:30/22:30 local time (LT) equatorial crossing. Aqua satellite provides information from early summer 2002 and crosses the equator at 01:30/13:30 LT. Cloud properties are determined using measurements by the Moderate Resolution Imaging Spectroradiometer (MODIS). MODIS provides measurements in 36 spectral channels [54]. Five of them (with the central wavelengths of $0.64,1.6$ (Terra) or 2.1 (Aqua), 3.7, 11, and $12 \mu \mathrm{m}$ ) are used in the CERES cloud mask [55]. Series of the spectral threshold tests (different between night and day) are used to determine cloudiness. In this study, the Single Scanner Footprint (SSF) product edition 2.5 was used. Data span the period from February 2000 (July 2002) to February 2010 for Terra (Aqua) satellite and come gridded on a regular 1-degree grid.

2.1.3. ISCCP. The International Satellite Cloud Climatology Project (ISCCP) was established in 1982 to collect and to analyze satellite radiance measurements for inferring spatial and temporal structure of clouds [56]. ISCCP involves measurements from weather geostationary satellites (GEO) (like GMS, GOES East, GOES West, Meteosat, MTSAT, and INSAT) and NOAA LEO satellites. Radiance data from a visible $(0.8 \mu \mathrm{m})$ and infrared $(11 \mu \mathrm{m})$ channels were obtained every 3 hours and then performed by the ISCCP Global Processing Center [57]. Data are intercalibrated between GEO and LEO satellites. Information on cloudiness characteristics is derived by using the spectral threshold test and a combination of the spatial and temporal uniformity tests [57]. We used the D2 product in this study [58]. Data are presented on a regular 2.5-degree grid and available from July 1983 to June 2008.

2.1.4. MODIS. A complete description of the MODIS cloud mask algorithm is given by Ackerman et al. [59]. Instead of 
TABLE 1: Cloudiness data information.

\begin{tabular}{|c|c|c|c|}
\hline Short name & $\begin{array}{l}\text { Dataset } \\
\text { Full name }\end{array}$ & Time period & Data resolution \\
\hline \multicolumn{4}{|c|}{ Satellite observations } \\
\hline APP-x & $\begin{array}{l}\text { Extended Advanced very high-resolution radiometer } \\
\text { (AVHRR) Polar Pathfinder Product }\end{array}$ & $01 / 1982-12 / 2004$ & $25 \mathrm{~km}$ \\
\hline CERES Terra & \multirow{2}{*}{$\begin{array}{l}\text { Clouds and the Earth's Radiant Energy System SSF Product } \\
\text { Edition } 2.5 \text { (board on Terra and Aqua) }\end{array}$} & $02 / 2000-02 / 2010$ & \multirow{2}{*}{$1^{\circ}$} \\
\hline CERES Aqua & & 07/2002-02/2010 & \\
\hline ISCCP & $\begin{array}{l}\text { International Satellite Cloud Climatology Project D2 } \\
\text { Product }\end{array}$ & 07/1983-06/2008 & $2.5^{\circ}$ \\
\hline MODIS Terra & \multirow{2}{*}{$\begin{array}{l}\text { Moderate-Resolution Imaging Spectroradiometer series } 5 \\
\text { product (board on Terra and Aqua) }\end{array}$} & 02/2000-12/2009 & \multirow{2}{*}{$1^{\circ}$} \\
\hline MODIS Aqua & & $07 / 2002-12 / 2009$ & \\
\hline PATMOS- $\mathrm{x}$ & AVHRR Pathfinder Atmosphere extended (version 5) & $01 / 1982-12 / 2009$ & $1^{\circ}$ \\
\hline \multicolumn{4}{|c|}{ Surface observations } \\
\hline EECRA & Extended Edited Cloud Report Archive & $01 / 1971-12 / 1996$ & $5^{\circ}$ \\
\hline \multicolumn{4}{|c|}{ Reanalyses data } \\
\hline ERA-40 & \multirow{2}{*}{$\begin{array}{l}\text { European Centre for Medium-Range Weather Forecasts } \\
\text { (ECMWF) Reanalyses }\end{array}$} & 01/1979-08/2002 & $2.5^{\circ}$ \\
\hline ERA-Interim & & 01/1989-12/2009 & $1.5^{\circ}$ \\
\hline JRA-25 & Japan Meteorological Agency Reanalysis & 01/1979-12/2009 & $2.5^{\circ}$ \\
\hline NASA-MERRA & $\begin{array}{l}\text { National Aeronautics and Space Administration (NASA) } \\
\text { Modern Era Reanalysis for Research and Applications }\end{array}$ & 01/1979-03/2009 & $0.5^{\circ}$ \\
\hline NCEP-CFSR & $\begin{array}{l}\text { National Centers for Environmental Prediction (NCEP) } \\
\text { Climate Forecast System Reanalysis }\end{array}$ & $01 / 1979-12 / 2009$ & $0.5^{\circ}$ \\
\hline NCEP/DOE & NCEP/Department of Energy & 01/1979-01/2008 & $\begin{array}{l}\sim 1.9^{\circ} \\
\text { (Gaussian) }\end{array}$ \\
\hline NCEP/NCAR & NCEP/National Center for Atmospheric Research & $01 / 1979-12 / 2008$ & $\begin{array}{l}\sim 1.9^{\circ} \\
\text { (Gaussian) }\end{array}$ \\
\hline NOAA-CIRES 20CR & $\begin{array}{l}\text { National Oceanic and Atmospheric } \\
\text { Administration-Cooperative Institute for Research in } \\
\text { Environmental Sciences (NOAA-CIRES) 20th Century } \\
\text { Reanalysis }\end{array}$ & $01 / 1979-12 / 2008$ & $\begin{array}{l}\sim 1.9^{\circ} \\
(\text { Gaussian })\end{array}$ \\
\hline
\end{tabular}

the CERES algorithm, 14 of 36 spectral channels of MODIS instruments are used to derive cloudiness characteristics ( 2 visible, 4 near infrared, and 8 infrared channels). The MODIS cloud mask algorithm includes series of the spectral threshold tests and a combination of the spatial and temporal uniformity tests. Additional tests are applied specially for the polar regions [25]. Cloud data from the collection 5 [60] were used in this study. These data are in a good agreement with active lidar and radar observations [61]. Data span the period from February 2000 (July 2002) to December 2009 for Terra (Aqua) satellite and come gridded on a regular 1-degree grid.

2.1.5. PATMOS- $x$. The Pathfinder Atmosphere extended (PATMOS- $\mathrm{x}$ ) cloudiness dataset is the longest one that based on satellite measurements (AVHRR sensors on NOAA LEO). We used the PATMOS- $x$ version 5 in this study [62]. Data are presented on a regular 1-degree grid and available from January 1982 to December 2009. The Naïve Bayesian methodology has been applied in the PATMOS$\mathrm{x}$ version 5 . Under this methodology, the cloud mask tests were reformulated as the Bayesian classifiers. An analysis of collocated LEO NOAA-18 and CALIPSO observations [47] was used to automatically and globally derive 6 Bayesian classifiers. They are computed separately for 7 surface types used in the final algorithm. These classifiers come from the clouds from AVHRR extended (CLAVR-x) cloud mask algorithm [63] based on series of spectral threshold tests. A complete description of these data is given by Heidinger et al. [62].

Table 2 presents summarized information on the satellite observations and the cloud mask algorithms.

\subsection{Surface Observations}

2.2.1. EECRA. The Extended Edited Cloud Report Archive (EECRA) is a global cloud climatology derived from surface synoptic weather reports based on visual observations from ships and land meteorological stations [64]. Cloudiness observations are made visually by human observers every three or six hours. In this study, we used data from EECRA E-series, which are presented on a regular 5-degree grid [26] and cover the period from January 1972 to December 1996. These data include only weather reports which passed a series of quality-control checks, like the "moonlight criterion" [26, 65], the data homogeneity, and so forth. 
TABLE 2: Satellite-based datasets information.

\begin{tabular}{|c|c|c|c|c|c|}
\hline Dataset & Satellite & $\begin{array}{l}\text { Spectral channels (visible } \\
\text { (VIS), near infrared (NIR), } \\
\text { infrared (IR)) }\end{array}$ & $\begin{array}{l}\text { Time of } \\
\text { observations (local } \\
\text { time) }\end{array}$ & $\begin{array}{l}\text { Instrument } \\
\text { resolution / swath } \\
(\mathrm{km})\end{array}$ & Cloud detection algorithm \\
\hline APP-x & LEO (NOAA) & $1 \mathrm{VIS}+1 \mathrm{NIR}+3 \mathrm{IR}$ & $\sim 14: 00,2: 00$ & $1-4 / \sim 3000$ & $\begin{array}{l}\text { A combination of the spectral and } \\
\text { temporal uniformity tests which are } \\
\text { tuned specially for the polar regions } \\
{[52] \text {. }}\end{array}$ \\
\hline CERES & $\begin{array}{l}\text { LEO (Terra, } \\
\text { Aqua) }\end{array}$ & $1 \mathrm{VIS}+1 \mathrm{NIR}+3 \mathrm{IR}$ & $\begin{array}{l}\text { 10:30, } 22: 30 \\
\text { (Terra) } \\
01: 30,13: 30 \\
\text { (Aqua) }\end{array}$ & $0,25-1 / 2330$ & $\begin{array}{l}\text { Series of the spectral threshold tests } \\
\text { (different between night and day) [55]. }\end{array}$ \\
\hline ISCCP & $\begin{array}{l}\mathrm{GEO}+\mathrm{LEO} \\
(\mathrm{NOAA})\end{array}$ & $1 \mathrm{VIS}+1 \mathrm{IR}$ & every 3 hour & $4-7 /-$ & $\begin{array}{l}\text { The spectral threshold test and a } \\
\text { combination of the spatial and } \\
\text { temporal uniformity tests [57]. }\end{array}$ \\
\hline MODIS & $\begin{array}{l}\text { LEO (Terra, } \\
\text { Aqua) }\end{array}$ & $1 \mathrm{VIS}+1 \mathrm{NIR}+3 \mathrm{IR}$ & $\begin{array}{l}\text { 10:30, } 22: 30 \\
\text { (Terra) } \\
01: 30,13: 30 \\
\text { (Aqua) }\end{array}$ & $0,25-1 / 2330$ & $\begin{array}{l}\text { Series of the spectral threshold tests } \\
\text { and a combination of the spatial and } \\
\text { temporal uniformity tests. Special tests } \\
\text { for the polar regions }[59,60] \text {. }\end{array}$ \\
\hline PATMOS- $\mathrm{x}$ & LEO (NOAA) & $1 \mathrm{VIS}+1 \mathrm{NIR}+3 \mathrm{IR}$ & $14: 00,2: 00$ & $1-4 / \sim 3000$ & $\begin{array}{l}\text { CLAVR-x (series of the spectral } \\
\text { threshold tests) + Naïve Bayesian } \\
\text { methodology [62]. }\end{array}$ \\
\hline
\end{tabular}

2.3. Reanalyses Data. Reanalyses are a synthesis of the observations and model physics. Reanalyses assimilate different observations of the key atmospheric variables and provide historical gridded fields for the whole atmosphere state at any given time (usually every 6 hours). We used information on cloudiness from 8 global reanalyses in our intercomparison (Tables 1 and 3). The following observations are assimilated in the majority of reanalyses: surface pressure from weather stations reports; surface pressure, temperature, humidity and wind from ship and buoys; upper-air wind, temperature and humidity from radiosondes, dropsondes, and balloons; temperature- and humidity-sensitive radiance from satelliteborne instruments; wind and temperature from aircrafts; cloud-tracked winds from geostationary satellites [66, 67]. New reanalyses (like NASA-MERRA, NCEP-CFSR, and ERAInterim) assimilate additional satellite-derived information like ozone profiles or oceanic wave height $[68,69]$, whilst the NOAA-CIRES 20CR reanalysis is based only on pressure data [70].

Different reanalyses have different cloud prediction schemes. In particular, a diagnostic scheme where clouds are parameterized based on an empirical relationship with relative humidity is used in NCEP/NCAR and NCEP/DOE reanalyses. Convective cloudiness is derived from the convective precipitation rate $[66,71,72]$. In JRA-25 reanalysis, cloud fraction is estimated diagnostically from total water mixing ratio and liquid water potential temperature $[73,74]$. In NCEP-CFSR, NASA-MERRA, and NOAA-CIRES 20CR reanalyses, cloud cover is derived from cloud condensate which is a prognostic variable with a simple cloud microphysics $[69,70,75,76]$. A fully prognostic approach for cloud fraction due to the mass balance equations for cloud water/ice and cloud air is applied only in the European reanalyses $[15,67,68,77]$. The method of the cloud overlap assumption is an additional factor that contributes to differences in the cloud representations in different reanalyses [15]. For instance, the random cloud overlap is used in NCEP/NCAR reanalysis, while the maximum/random overlap is used in NCEP-CFSR reanalysis [69]. It should have noted that none of the reanalyses assimilate cloud fraction directly from observations.

Table 3 presents summarized information about reanalyses data.

Here, we analyzed monthly means of total cloud fraction with annual and seasonal averaging. All individual climatologies were obtained by averaging for time periods that are pointed out in Table 1.

\section{Results}

3.1. Annual and Seasonal Means Total Cloud Fraction. Annual and seasonal means total cloud fraction (TCF) from different data over the Arctic is shown in Figure 1. According to observations, the annual-mean TCF (Figure 1(a)) varies between $0.67 \pm 0.01$ for CERES Aqua and $0.73 \pm 0.03$ for APP$\mathrm{x}$ data. According to all observations, the annual mean TCF is greater over the ocean (between $0.70 \pm 0.02$ for CERES Terra and $0.78 \pm 0.03$ for PATMOS-x) than over land (between $0.64 \pm 0.01$ for CERES Aqua and $0.70 \pm 0.03$ for APP-x data). According to reanalyses, the annual mean TCF varies in wider range from $0.48 \pm 0.01$ for NCEP/NCAR to $0.88 \pm$ 0.01 for 20CR. NASA-MERRA reanalysis has the best fit to observations with annual mean TCF equal to $0.71 \pm 0.01$. In general, reanalyses have lower value of the interannual standard deviation of TCF than observations, which indicate to lower interannual variability in reanalyses compared to observations.

In winter (Figure 1(b)), observations demonstrate worse agreement among each other. Winter mean TCF varies from 


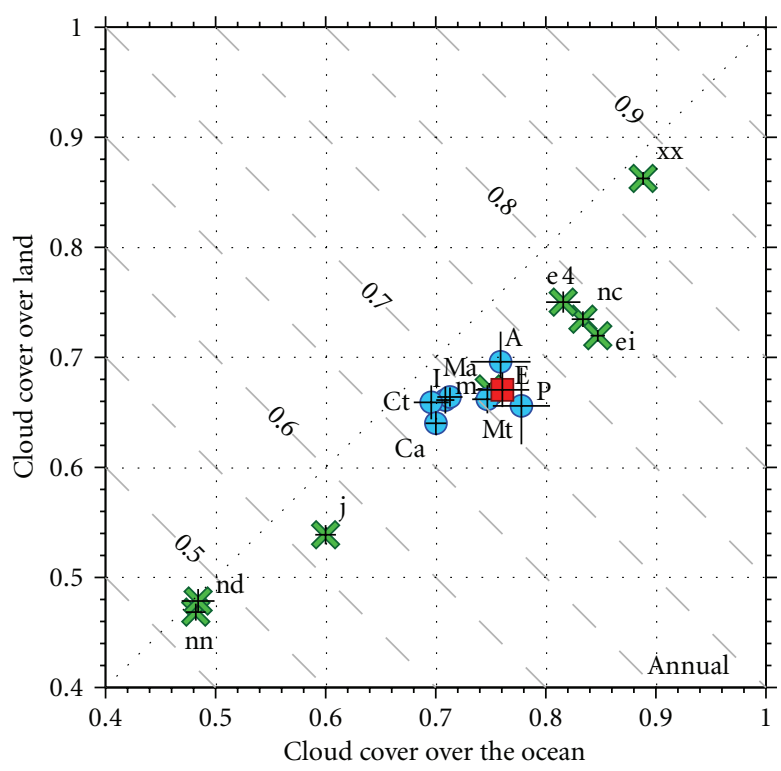

(a)

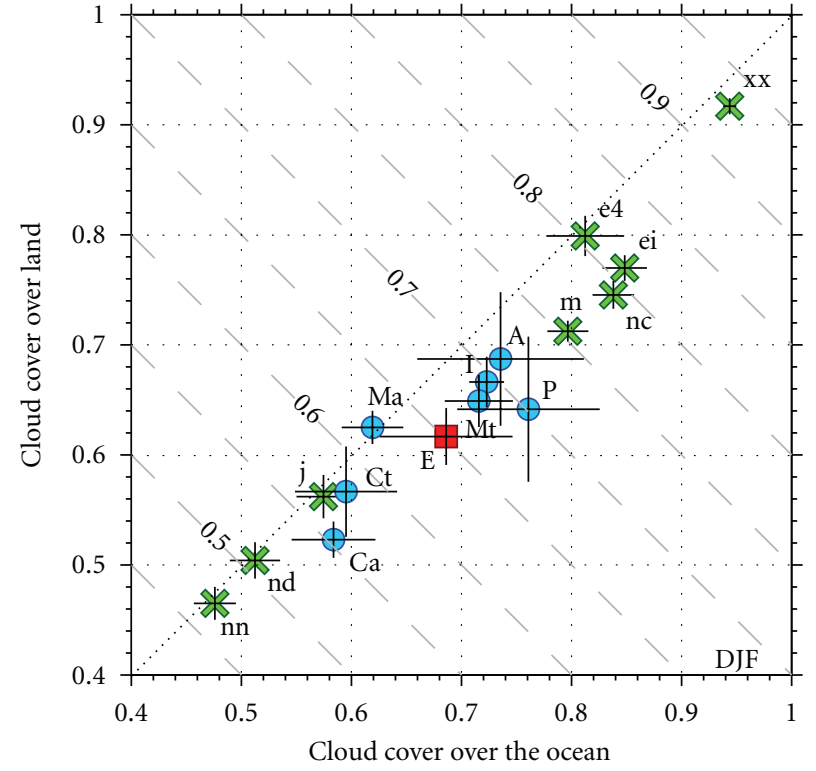

(b)

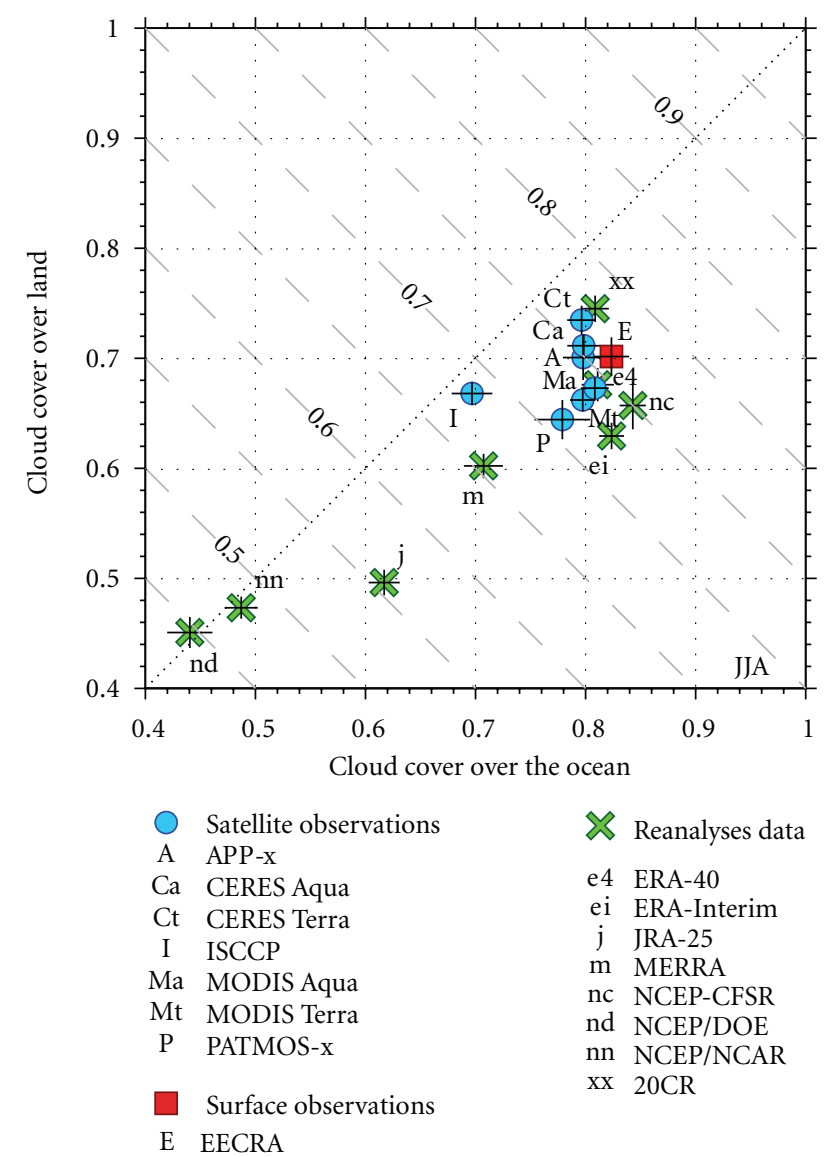

(c)

Figure 1: Annual (a), December-January-February (b), and June-July-August (c) mean of TCF over the Arctic (north of $60^{\circ} \mathrm{N}$ ) from different data. The error bars correspond to the standard deviation (in the interannual variability) of each data (separately for land and the ocean). The abscissa corresponds to TCF over the ocean, and the ordinate corresponds to TCF over land. The inclined long-dashed lines correspond to TCF over land and the ocean (their slope is equal to the land-ocean ratio in the Arctic). 
TABLE 3: Reanalyses information.

\begin{tabular}{|c|c|c|}
\hline Dataset & $\begin{array}{l}\text { Atmospheric model and its resolution/data assimilation } \\
\text { method/reanalysis features }\end{array}$ & Predictors for cloud fraction \\
\hline ERA-40 [67] & ECMWF cy13r4 T159 (80 km) L60 6 hr/3D VAR & $\begin{array}{l}\text { Cloud fraction is fully prognostic (due to the mass } \\
\text { balance equations for cloud water/ice and cloud air) } \\
\text { [77] }\end{array}$ \\
\hline ERA-Interim [68] & $\begin{array}{l}\text { ECMWF cy29r1 T255 }(50 \mathrm{~km}) \mathrm{L} 606 \mathrm{hr} / 4 \mathrm{D} \\
\text { VAR/weather station observations and new satellite } \\
\text { data are assimilated }\end{array}$ & $\begin{array}{l}\text { The same as for ERA-40 with several important } \\
\text { modifications [68] }\end{array}$ \\
\hline JRA-25 [74] & JMA/CRIEPI T160 (120 km) L40 6 hr/3D VAR & $\begin{array}{l}\text { Water mixing ratio and the liquid water potential } \\
\text { temperature [73] }\end{array}$ \\
\hline $\begin{array}{l}\text { NASA-MERRA } \\
{[76]}\end{array}$ & $\begin{array}{l}\text { GEOS-5 } 50 \mathrm{~km} \mathrm{L72} 6 \mathrm{hr} / 3 \mathrm{D} \text { VAR/new satellite data are } \\
\text { assimilated }\end{array}$ & $\begin{array}{l}\text { Prognostic cloud and a single-phase condensate with } \\
\text { two species of condensate: "anvil" (originating from } \\
\text { detraining convection) and large scale [78] }\end{array}$ \\
\hline NCEP-CFSR [69] & $\begin{array}{l}\text { NCEP GSI T382 }(32 \mathrm{~km}) \mathrm{L} 646 \mathrm{hr} / 3 \mathrm{D} \\
\text { VAR/atmospheric model is coupled with the ocean, } \\
\text { land, and sea ice analysis }\end{array}$ & $\begin{array}{l}\text { Prognostic cloud condensate, water mixing ratio, and } \\
\text { the liquid water potential temperature }[73,78]\end{array}$ \\
\hline $\begin{array}{l}\text { NCEP/DOE [72] } \\
\text { NCEP/NCAR [66] }\end{array}$ & NCEP T62 (210 km) L28 6hr / 3D VAR & $\begin{array}{l}\text { Relative humidity (empirical relationship), prognostic } \\
\text { convective precipitation rate }[71]\end{array}$ \\
\hline $\begin{array}{l}\text { NOAA-CIRES } \\
20 \mathrm{CR}[70]\end{array}$ & $\begin{array}{l}\text { NCEP GFS T62 }(210 \mathrm{~km}) \mathrm{L} 286 \mathrm{hr} / \text { ensemble Kalman } \\
\text { filter/only surface pressure is assimilated }\end{array}$ & $\begin{array}{l}\text { Prognostic cloud condensate, water mixing ratio, and } \\
\text { the liquid water potential temperature }[73,78]\end{array}$ \\
\hline
\end{tabular}

$0.55 \pm 0.02$ for CERES Aqua to $0.71 \pm 0.07$ for APP-x. MODIS Aqua is only the one dataset that shows more TCF over land than over the ocean. In general, TCF over land is between $0.52 \pm 0.02$ (for CERES Aqua) and $0.68 \pm 0.06$ (for APP$\mathrm{x}$ ), and TCF over the ocean is between $0.58 \pm 0.04$ (for CERES Aqua) and $0.76 \pm 0.06$ (for PATMOS-x). According to JRA-25 reanalysis, TCF fits this range. It is less (about 0.5 ) according to NCEP/NCAR and NCEP/DOE and greater according to other reanalyses (up to $0.93 \pm 0.01$ for NOAACIRES 20CR). The reverse is true for summer (Figure 1(c)) when reanalyses show less TCF than observations (or equal to them). Observations are in a better agreement in summer than in winter, especially over the ocean where TCF is close to 0.8 except for ISCCP $(0.7 \pm 0.02)$. Over land, summer mean TCF varies from $0.64 \pm 0.02$ (for PATMOS-x) to $0.82 \pm 0.02$ (for EECRA). Over the entire Arctic, summer mean TCF is between $0.68 \pm 0.01$ (for ISCCP) and $0.76 \pm 0.01$ (for CERES Terra).

Interannual variability is higher in winter (its standard deviation is up to 0.07 over land and up to 0.08 over the ocean) than in summer (its interannual standard deviation does not exceed 0.3 ) according to all observation-derived data. However, the interannual variability almost does not depend on season according to reanalyses, which may indicate that high winter variability of observation-derived TCF is partly associated with uncertainties in observations $[8,79]$.

3.2. Annual Cycle of Total Cloud Fraction. Figure 2 shows annual cycle of TCF over the Arctic. The maximum of TCF is noted at the end of polar day (August-September), and its time concurs with the time of the minimum of the sea ice extent in the Arctic $[45,51]$. The minimum of TCF is noted at the end of polar night (February-April) (Figure 2(a)).
According to the most of observations, the Arctic land-mean TCF has a prominent annual cycle (Figure 2(b)) with the maximum in August-October (0.64-0.78) and the minimum in December-March (0.50-0.68). According to CERES Aqua, land-mean TCF has the highest amplitude of annual cycle (close to 0.3). Annual cycle of cloudiness over the ocean (Figure 2(c)) is also prominent. High values of ocean-mean TCF are noted from May to October (about 0.8 excluding ISCCP). Low values are noted from November to April (0.55-0.75). However, months with the maximum (or the minimum) varied between different data. For instance, it is June for APP-x, July for CERES Terra, August for MODIS (Terra and Aqua), and September for EECRA (Figure 2(c)). According to Curry et al. [16], the summer maximum is associated with low-level stratiform cloudiness, while in winter cyclones-induced upper-level clouds dominate (see also [10]).

Meanwhile, the annual cycle of TCF according to PATMOS- $x$ and ISCCP data is not revealed clearly. According to PATMOS- $x$, it has two maximums (in May and in September) and two minimums (in July and in DecemberMarch). Presumably, this may be associated with an overestimation of stratiform clouds (as shown in [10], these clouds also have the annual distribution with two minimums and two maximums) and an underestimation of the other cloud types. According to ISCCP, land-mean TCF is 0.66 , and ocean-mean TCF is 0.71 during the whole year. As pointed out by Schweiger et al. [80], ISCCP is in a better agreement with surface observations in summer (with 10$20 \%$ underestimation) and in a worse agreement in winter mostly because of a systematic positive bias in surface temperature retrieval. 


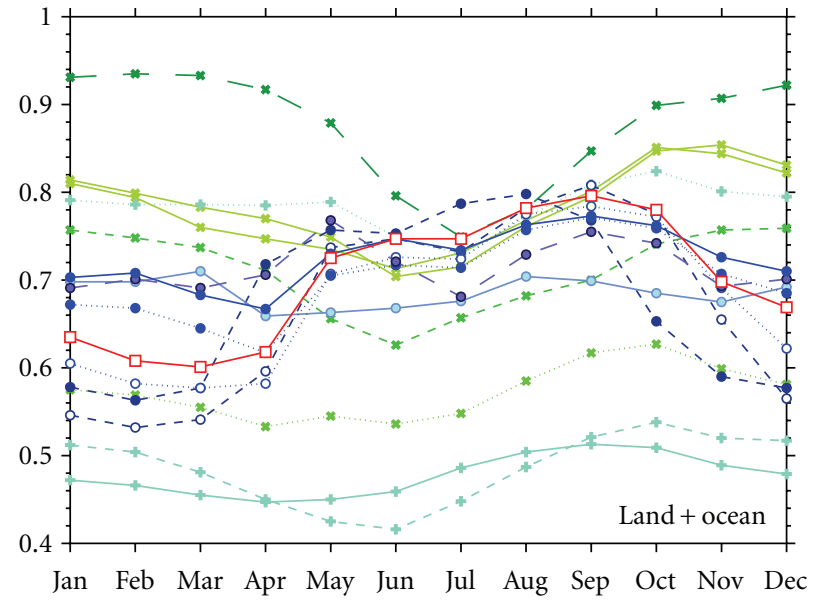

(a)

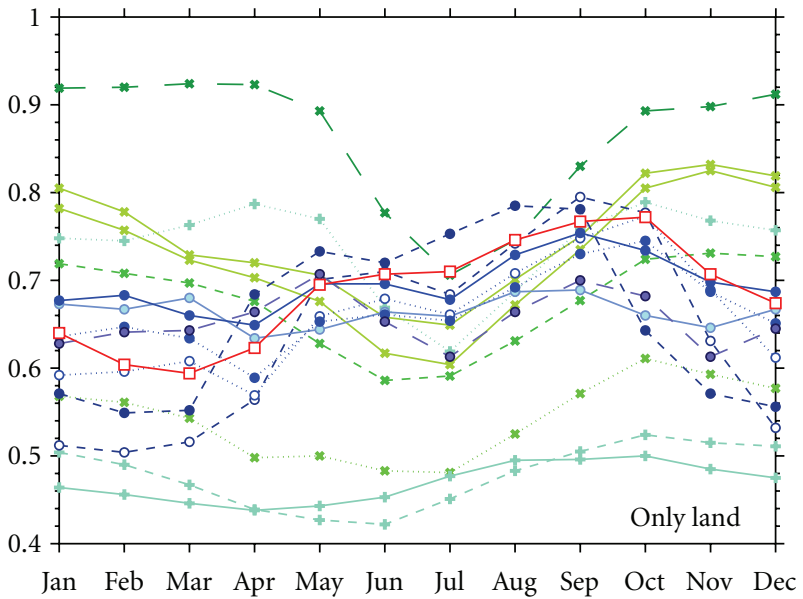

(b)

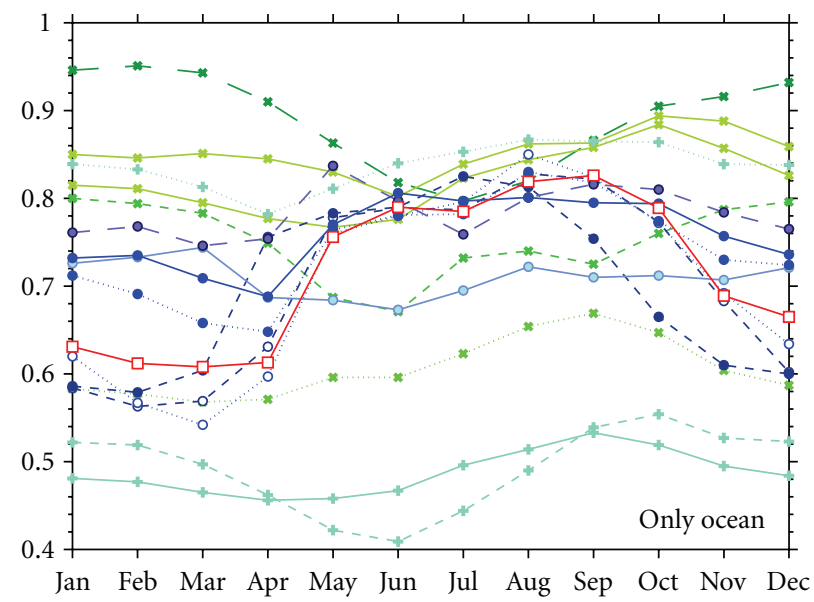

Satellite observations

$$
\begin{array}{ll}
- & \text { APP } \\
-0- & \text { CERES Aqua } \\
-\bullet- & \text { CERES Terra } \\
-0- & \text { ISCCP } \\
\text {.०. } & \text { MODIS Aqua } \\
- & \text { MODIS Terra } \\
-0- & \text { PATMOS-x }
\end{array}
$$

Surface observations

$$
\begin{array}{ll}
\text { Reanalyses data } \\
* \quad \text { ERA-40 } \\
* \quad \text { ERA-Interim } \\
-\cdots \quad \text { JRA-25 } \\
-* \quad \text { MERRA } \\
-\cdots \quad \text { NCEP-CFSR } \\
-4-\quad \text { NCEP/DOE } \\
-\quad \text { NCEP/NCAR } \\
-\quad \text { 20CR }
\end{array}
$$

$-\square-$ EECRA

FIgURE 2: The annual cycle of TCF averaging over the entire Arctic (a), only over land (b), and over the ocean (c).

According to reanalyses, the annual cycle of TCF does not match well with the observational one. Closer agreement between most of reanalyses and observations in TCF values is noted during the sunlit part of the year (see also Figure 1(c)). NCEP/NCAR, NCEP/DOE, and JRA-25 reanalyses show lower values of TCF during the whole year. In general, according to reanalyses, the annual cycle of TCF is shifted by 1-2 months compared to observations. It has the minimum in early summer (June-July) and reaches the maximum in late autumn-early winter (from
October to January). NOAA-CIRES 20CR reanalysis (which is based on pressure data only [70]) shows the worst agreement with observations.

3.3. Intercomparison of Total Cloud Fraction Spatial Distribution. Spatial distribution of the annual mean TCF (not shown) is associated with the spatial distribution of the annual mean surface skin temperature. According to all observations, the annual mean TCF minimum occurs over the northeastern part of Greenland (it varies from 0.4 for 


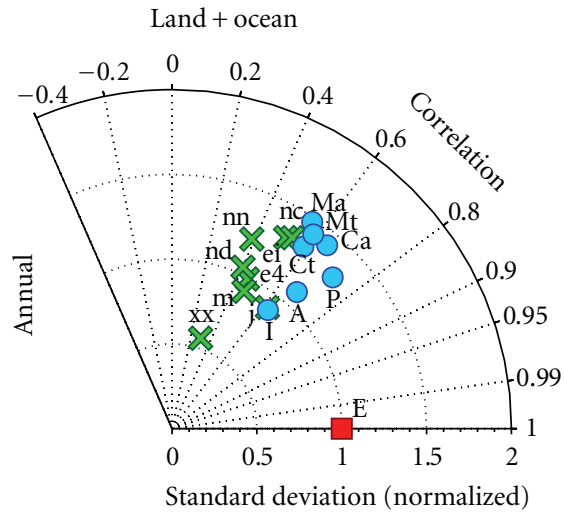

(a)

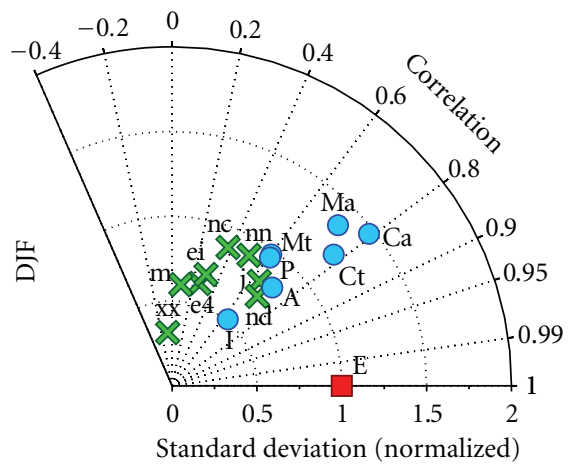

(d)

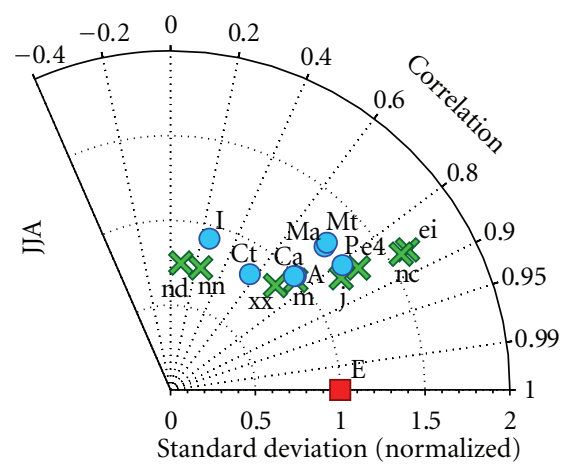

(g)

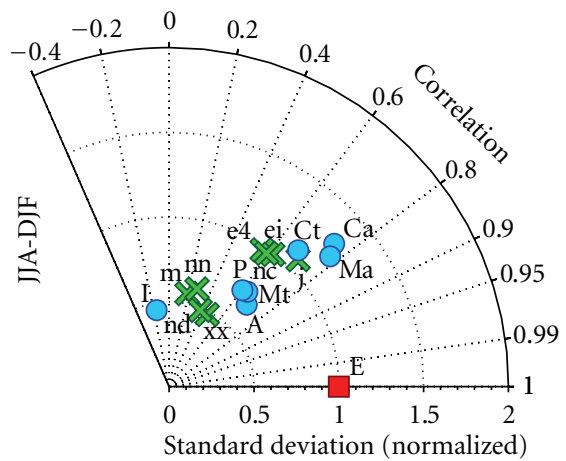

(j)

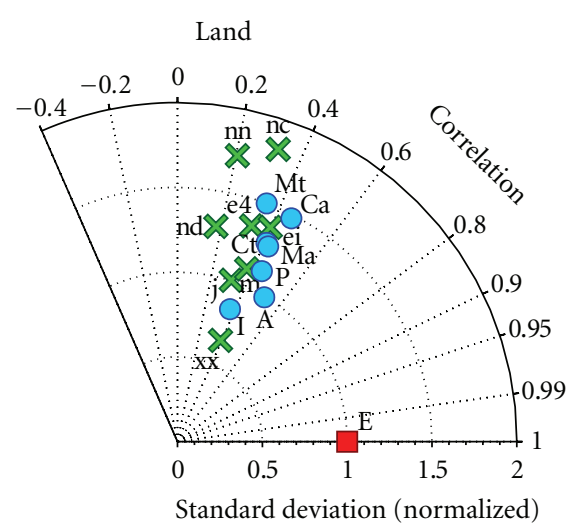

(b)

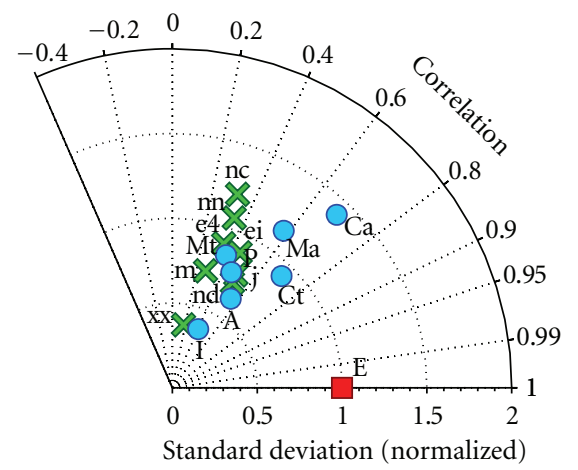

(e)

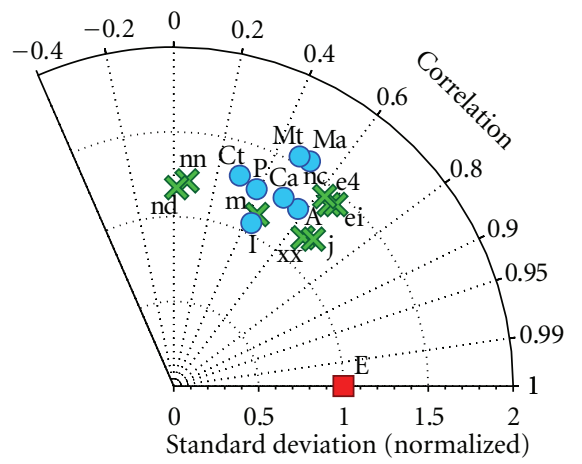

(h)

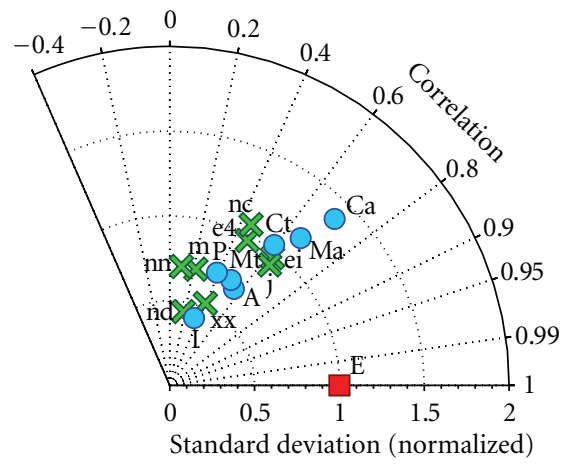

(k)

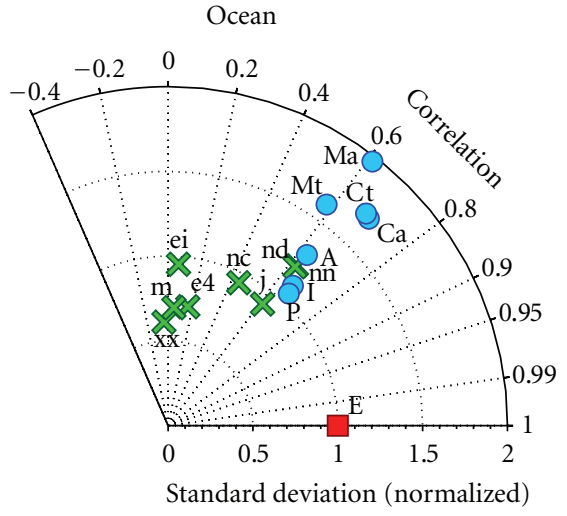

(c)

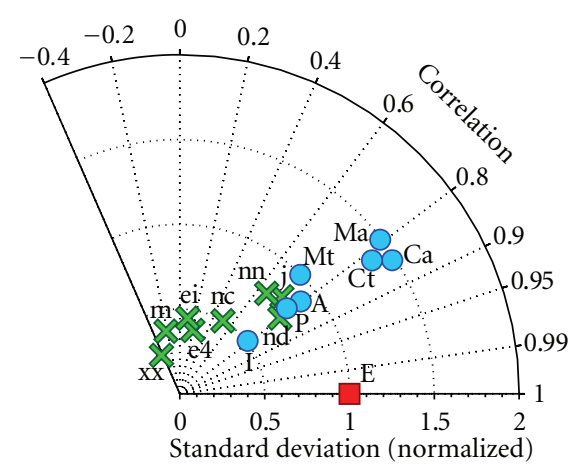

(f)

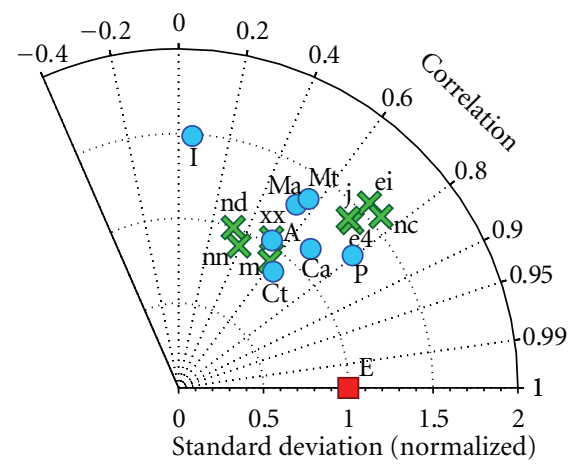

(i)

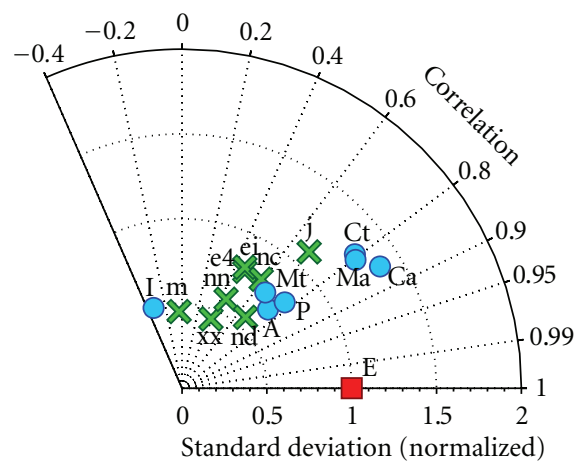

(1)

FIGURE 3: Normalized pattern statistics showing differences among different observational and reanalyses TCF spatial distribution (the reference data is surface-derived data EECRA) over the entire Arctic (a, d, g, j), only land (b, e, h, k), and only the ocean (c, f, i, l) for annual means (a, b, c), December-January-February (DJF) means (d, e, f), June-July-August (JJA) means (g, h, i), and seasonal differences (JJA-DJF) $(\mathrm{j}, \mathrm{k}, \mathrm{l})$. The radial distances from the origin are proportional to the spatial standard deviation (SSTD) of each data (normalized to EECRA SSTD). The spatial correlation between EECRA and other data is given by the azimuthal position. Acronyms are the same as for Figure 1. 


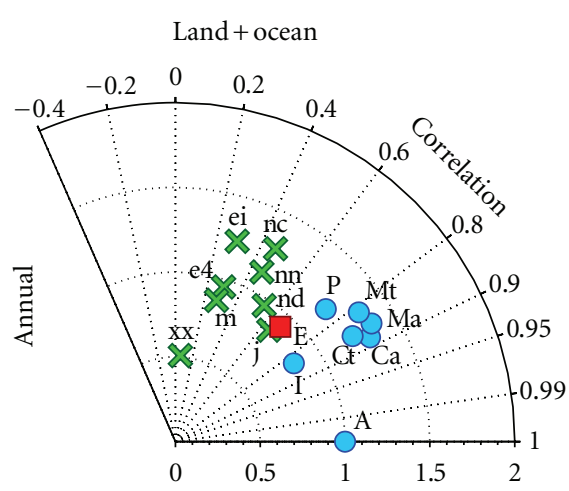

Standard deviation (normalized)

(a)

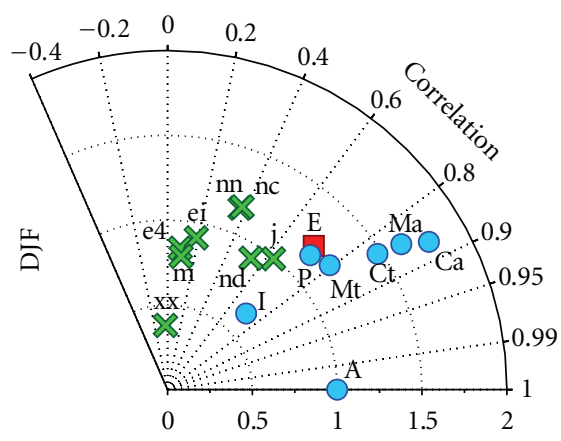

Standard deviation (normalized)

(d)

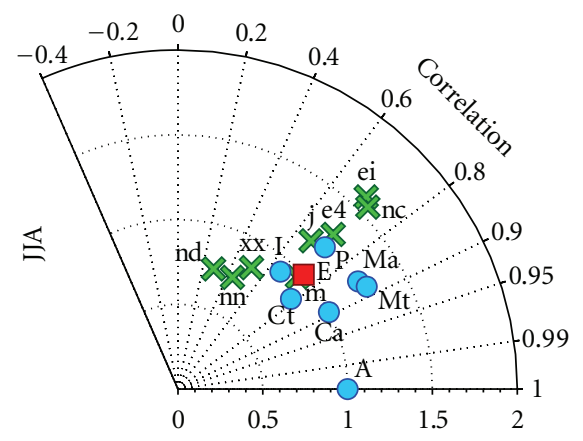

Standard deviation (normalized)

(g)

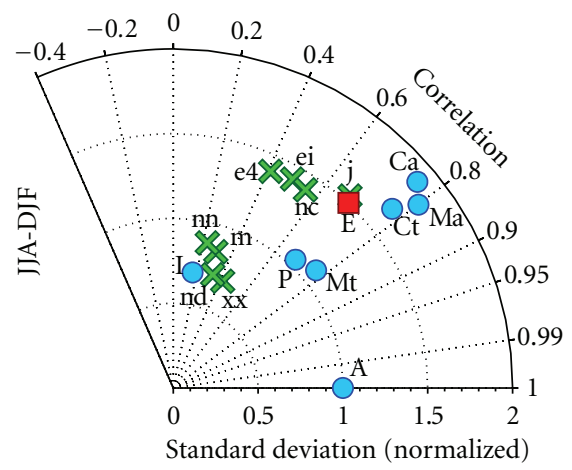

(j)

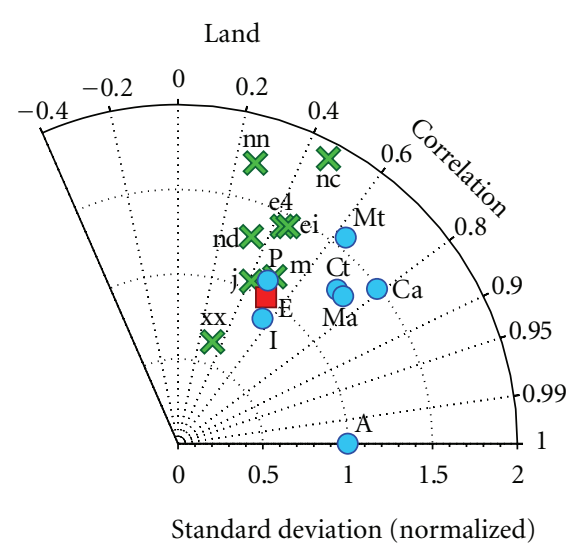

(b)

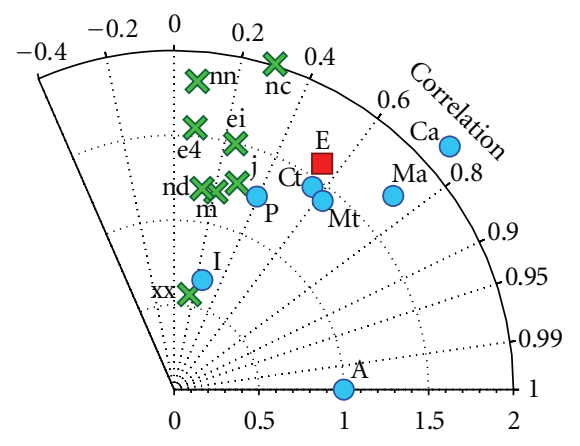

Standard deviation (normalized)

(e)

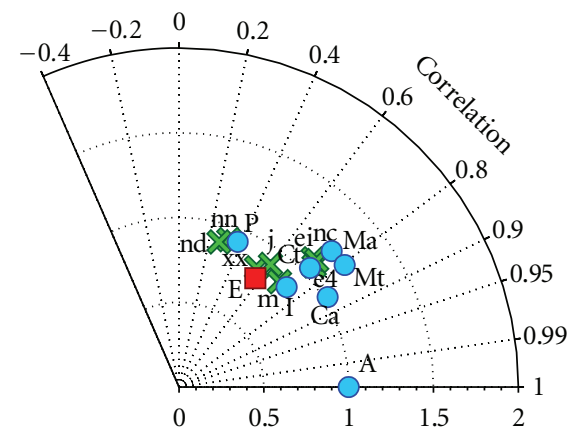

Standard deviation (normalized)

(h)

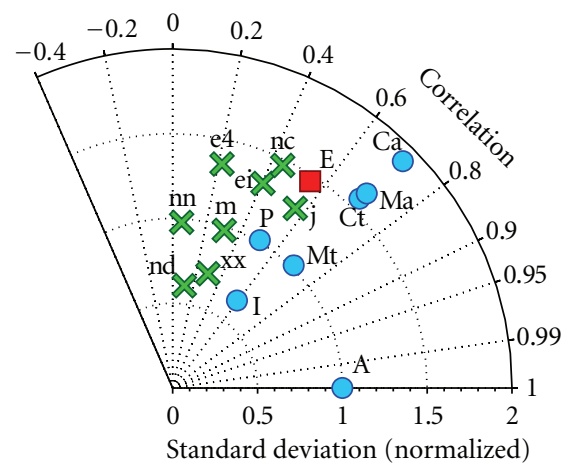

(k)

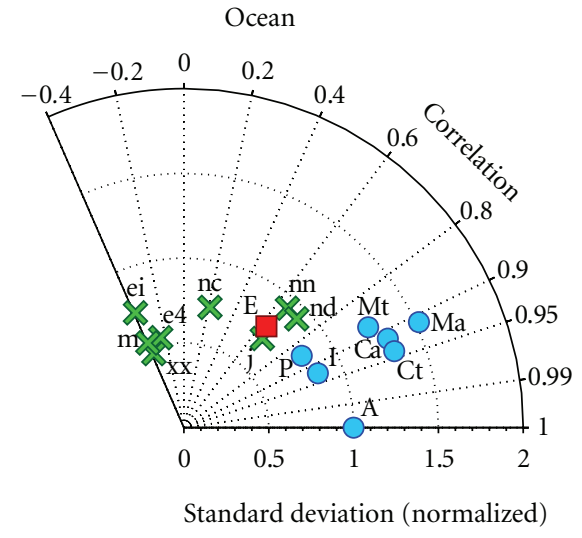

(c)

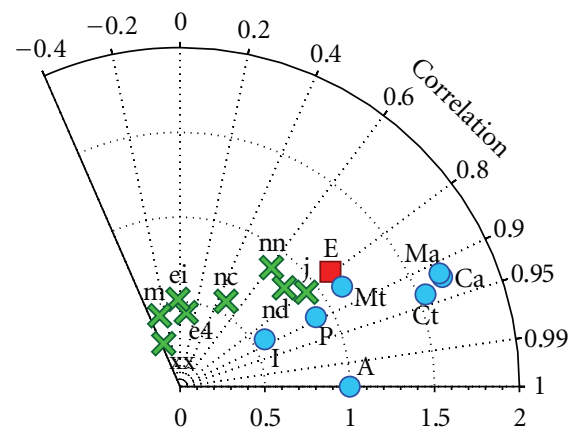

Standard deviation (normalized)

(f)

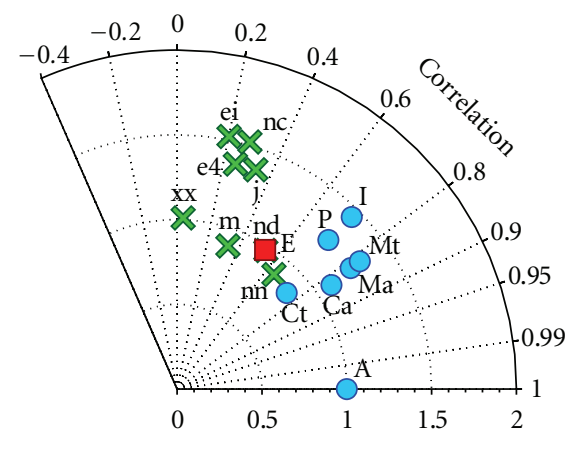

Standard deviation (normalized)

(i)

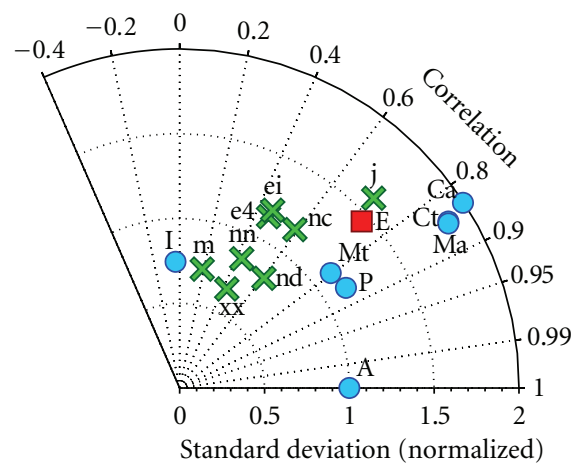

(1)

FIgUre 4: The same as Figure 3 but with satellite-derived APP-x as the reference data. 
MODIS Terra to 0.6 for APP-x) and collocates with the skin surface temperature minimum (it is down to $-30^{\circ} \mathrm{C}$ [51]). Reanalyses also show the minimum of TCF over Greenland (it varies from 0.2 for NCEP/NCAR to 0.8 for NOAA CIRES 20CR). The highest value of the annual mean TCF is over the warmest part of the Arctic (The Norwegian and Barents Sea). It is from $0.8-0.85$ for EECRA and ISCCP to $0.9-1.0$ according to other data. This high value of TCF is somewhat captured in reanalyses. They produce low values of the annual mean TCF over northern Eurasia, the Canadian Arctic archipelago, Alaska, and the Canadian part of the Arctic Ocean (particularly, over the Beaufort Sea) and high values over northern Europe, the Baffin Sea, and the central part of the Arctic Ocean. ERA-40, ERA-Interim, NASA-MERRA, and NOAA-CIRES 20CR reanalyses show the highest values of TCF over the central part of the Arctic Ocean but not over the Norwegian and Barents Sea as observations do.

To make a simultaneous intercomparison of the TCF spatial distribution from all data, we apply an approach that was introduced by Taylor [81]. All data were bilinearly interpolated to the uniform grid (EECRA grid with 5degree resolution was chosen). In this approach, different data are spatially correlated with the particular data that are presupposed to be the reference data. EECRA (Figure 3) and APP-x (Figure 4) data were chosen as the reference data for this analysis which was performed separately for annual and seasonal means, for the entire Arctic, only for the ocean, and only for land.

In general, satellite data show a closer agreement with each other than with surface observations. Coefficient of spatial correlation (R) between EECRA data and others (RE) varies from 0.5 to 0.7 for the annual mean TCF. RE is higher over the ocean $(0.5-0.8)$ than over land $(0.3-0.7)$ and nearly the same for different seasons. The coefficient of spatial correlation between APP-x data and others (RA) varies from 0.7 to 0.9 . RA for the annual mean TCF is higher over the ocean than over land (as well as RE). Over the ocean, RA is 0.6 for EECRA and $0.85-0.95$ for satellite-derived data. It is from 0.5 to 0.8 over land. Besides, RA for TCF over the ocean is higher in winter, and RA for TCF over land is higher in summer. This is presumably due to a mosaic structure of the underneath surface which depends on the season in an opposite manner for land and for the ocean. The ocean is covered by the ice during winter and is partially open in summer. In contrast, land is free from snow in summer (excluding Greenland) and is partially covered by snow in winter.

ISCCP has the worst agreement with other observations. Particularly RE for ISCCP is negative for seasonal difference over land and over the ocean. RA for ISCCP is negative over the ocean and close to zero over land. However, ISCCP shows nearly the same values of spatial standard deviation (SSTD) of TCF as EECRA and APP-x. In general, shortperiod datasets like CERES and MODIS show higher SSTD than long-period datasets.

Reanalyses reproduce SSTD of TCF comparable to observations during summer over the entire Arctic. However, reanalyses show lower values of SSTD of ocean-mean TCF than observations during the winter. The values of RE and RA for reanalyses are between 0.2 and 0.4 over land. This range is wider over the ocean (from 0 to 0.6). The European reanalyses and NOAA-CIRES 20CR have negative values of RA and RE over the ocean. During winter, RE and RA are also negative for NASA-MERRA reanalysis. Generally, reanalyses and observations are in closer agreement on the spatial distribution of TCF in summer than in winter. JRA25 reanalysis shows the best agreement with observations on the spatial distribution of TCF among all reanalyses.

3.4. Reasons for Data Discrepancies. Differences among various observations may be due to several reasons. First of all, these are differences in instruments and in cloud detection algorithms. Especially these differences are crucial under harsh arctic conditions where the snow/ice surface and the presence of low-troposphere inversions lead to very low thermal and radiance contrasts between clouds and underneath surface. Liu et al. [79] compared arctic cloudiness from MODIS and GeoPROF data (based on simultaneous lidar and radar observations from A-Train satellites CALIPSO and CloudSat) and found out that passive satellite observations can underestimate cloudiness by $10-20 \%$ over the snow/ice surface under nighttime conditions. Thus, a decrease of the sea ice extent could lead to an appearance of an instrumental cloudiness trend in long-term datasets. Alongside with real cloudiness trends, it also can contribute to differences obtained in our analysis because of the different averaging period chosen for different data (Table 1). Due to diurnal cycle of cloudiness, different time of observations may also influence data discrepancies $[33,82]$. According to [82], the differences between only-noon observations and four-timesa-day observations can reach $10 \%$ in tropics and do not exceed $5 \%$ in the Arctic. Differences in reanalyses mostly depend on different cloud prediction schemes, and methods of cloud overlap assumption [15].

To elucidate the main reason for data discrepancies, it is crucial to single out the regions with poor agreement among data. To reveal these regions, we interpolated all observations to the uniform grid (the robust EECRA grid was chosen). Annual and seasonal means of TCF were calculated for each observation-derived data and after that inter-data means and inter-data standard deviations of these individual means were obtained in each grid cell. Reanalyses were excluded from this analysis. Resulting values of the inter-data standard deviation (ISTD) in each grid cell are depicted in Figure 5.

We found the highest annual mean ISTD over Greenland and over the Arctic Ocean (particularly over the Canadian part) (Figure 5(a)). Meanwhile, over northern Eurasia and North America, ISTD is low, which indicates a good agreement among different data. In addition, ISTD is, respectively, low in regions with the dramatic sea ice extent loss such as the Beaufort Sea and Baffin Sea and the western part of the Greenland Sea [7].

For wintertime and for seasonal difference (Figures 5(b) and 5(d)), the highest values of ISTD are over the Canadian part of the Arctic Ocean and northeastern Eurasia (up to 0.2). According to Liu et al. [83] and Devasthale et al. [84], 


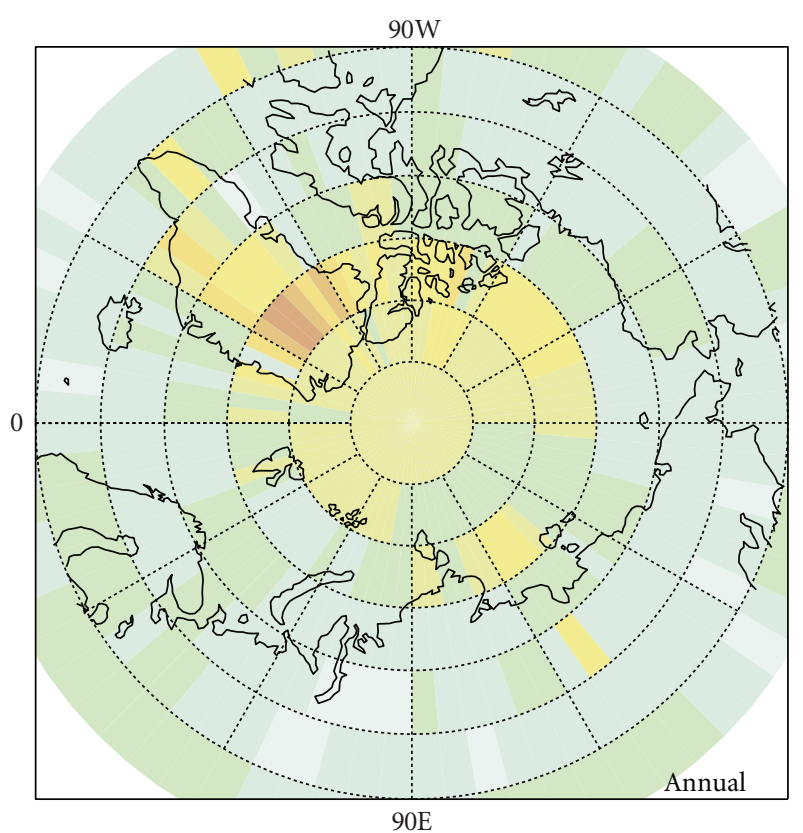

(a)
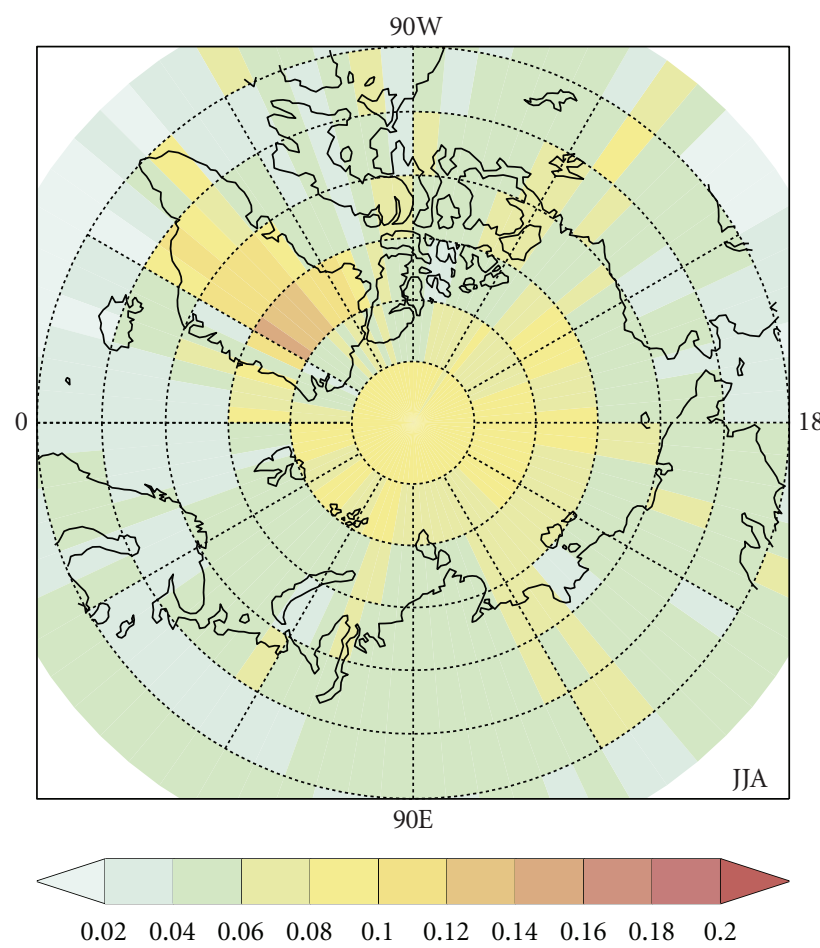

(c)

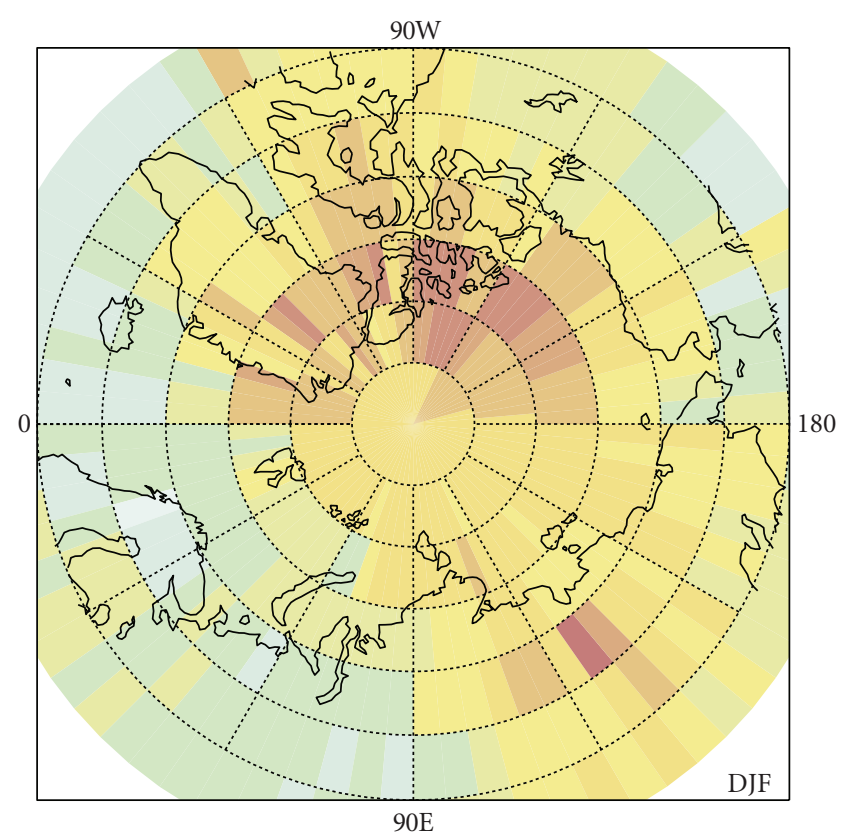

(b)
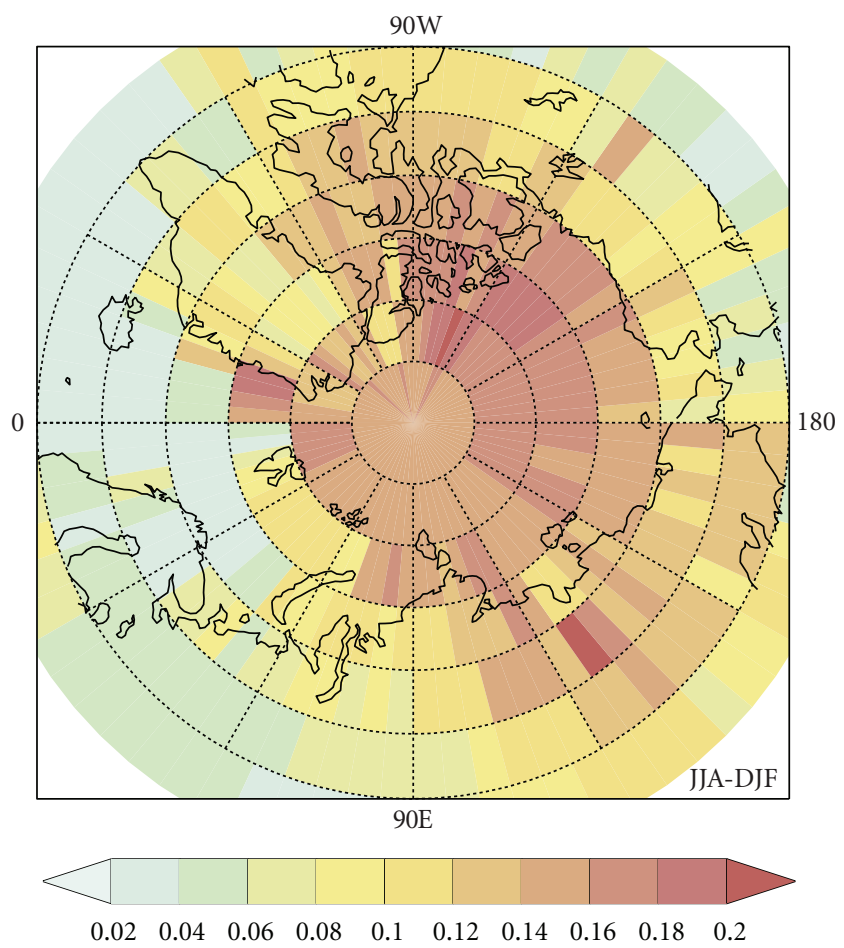

(d)

FIgURE 5: Distribution of inter-data standard deviation of TCF (reanalyses are excluded) for annual mean (a), December-January-February mean (DJF) (b), June-July-August mean (JJA) (c), and differences between JJA and DJF (d).

the strongest low-tropospheric temperature inversions occur in these regions. Relatively high ISTD over the Arctic Ocean in winter is mostly associated with ISCCP data, whose algorithm erroneously detects clear-sky ice crystal precipitation as cloudiness [16] and has a systematic positive bias in the surface temperature retrieval [80]. In general, other satellitederived datasets also have lower cloud detection capabilities during nighttime than daytime and over surfaces covered with the sea ice [79]. Ship observations from EECRA data also cannot provide suitable information over the central 
part of the Arctic Ocean in winter due to a small number of observations [26]. In summer (Figure 5(c)), ISTD is smaller than in winter. The highest values of ISTD are noted over the ice surface of Greenland. Thus, we speculate that the main reason for observations discrepancies is differences in the cloud-detection algorithms, especially when clouds are detected over the ice/snow surface (during the whole year) or over regions with the presence of the strong low-tropospheric temperature inversions (mostly in winter).

\section{Discussion and Conclusions}

The Arctic annual mean TCF is $0.70 \pm 0.03$ according to different observations. It is greater over the ocean $(0.74 \pm$ $0.04)$ than over land $(0.67 \pm 0.03)$. Different observations are in a better agreement in summer than in winter and over the ocean than over land for the Arctic mean TCF as well as for the spatial distribution of TCF. The interannual variability is higher in winter than in summer according to all observation-derived data, which may be associated with uncertainties in observations that are greater in winter than in summer. Total cloud fraction in the Arctic has the prominent annual cycle according to all observations excluding PATMOS- $x$ and ISCCP. The time of TCF maximum corresponds with the time of the sea ice extent minimum (early summer-late autumn) and vice versa (late spring) (see also [16]). This correspondence is also found in an interannual variability. Eastman and Warren [10] and Palm et al. [85] showed that TCF is greater during the years with the low sea ice extent and vice versa according to satellite data [85] and surface observations [10]. In general, reanalyses do not capture this feature of TCF annual cycle. According to most of the reanalyses, the maximum of TCF is shifted to October-November. NCEP/NCAR, NCEP/DOE, and JRA25 reanalyses show less TCF than observations during the whole year. Other reanalyses are in a close agreement with observations during summer, while in wintertime, they show noticeably higher values of TCF than observations.

Spatial distribution of the annual mean TCF collocates with the spatial distribution of the annual mean surface skin temperature. The annual mean TCF minimum occurs over the northeastern part of Greenland and collocates with the minimum of the skin surface temperature, whilst the annual mean TCF maximum is noted over the warmest part of the Arctic (the Norwegian and Barents Sea). Reanalyses capture the position of the TCF minimum correctly, but some of them erroneously show the highest values of TCF over the central part of the Arctic Ocean but not over the Norwegian and Barents Sea as observations do. In addition, reanalyses show higher spatial correlation of TCF with observations in summer than in winter and over the ocean than over land. The spatial distributions of TCF from different satellite observations are in a closer agreement over the ocean in winter and over land in summer. The presumable reason for this peculiarity is the mosaic structure of the underneath surface which depends on season in an opposite manner for land and for the ocean. This feature is not revealed when satellite data are compared with surface observations which do not depend on surface characteristics.

For the whole year, the greatest disagreement among observations was revealed in regions with the ice/snow surface. Furthermore, we found that agreement in winter is poor in regions with the presence of strong low-tropospheric temperature inversions. This can indicate the difference in the cloud-detection algorithms as the main reason for data discrepancies. Nonetheless, other reasons should also be taken into account (diurnal cycle, differences in averaging period). We should emphasize that we do not estimate here the quantitative input from different reasons into resulting discrepancies.

It is worth noting that surface and satellite observations and reanalyses define clouds slightly different. Particularly, human observers detect bases of the clouds, while satellite sensors observe tops of the clouds. Clouds are water condensates (water or ice) that are visible for human observers on surface or detectable for passive sensors on satellites. Thus, human observers as well as passive sensors can miss some small or semitransparent clouds, which are undetectable for them. Contrastingly, reanalyses define clouds independently for each model level and do not have a threshold on minimal amount of condensate that can be considered as cloud. These qualitative differences among different observational approaches should also be taken into account.

To determine real values of TCF over the Arctic in different seasons more evaluations are needed. Active sensors like radar and lidar have a potentially great capability to improve our knowledge about Arctic cloudiness especially during the cold portion of the year. However, these observations are still too short. Additionally, lidar could erroneously detect a thick Arctic haze layer as a cloud [79] and radar-derived cloudiness strongly depends on the applied thresholds [86].

At present, it is hard to distinguish the best observational dataset for the Arctic cloudiness. Further analyses should be carried out for the specific regions with the greatest disagreement among cloudiness datasets, particularly Greenland, the Canadian Arctic Archipelago, and the northern part of East Siberia.

\section{Acknowledgments}

The authors thank three anonymous reviewers for their helpful comments. They acknowledge the mission scientists and principal investigators who provided the data used in this research. APP- $x$ and PATMOS- $x$ data were obtained from the Cooperative Institute for Meteorological Satellite Studies, University of Wisconsin websites (http://stratus.ssec.wisc.edu/projects/app/app.html and http://cimss.ssec.wisc.edu/patmosx/). CERES data were obtained from the NASA Langley Research Center, Atmospheric Science Data Center. The ISCCP DX data are from the International Satellite Cloud Climatology Project data archives at NOAA/NESDIS/NCDC Satellite Services Group. MODIS data were obtained from Level 1 and Atmospheric Archive and Distribution System. EECRA data were obtained from Carbon Dioxide Information 
Analysis Center website (http://cdiac.ornl.gov/). ERA-40 and ERA-Interim data have been provided by ECMWF. JRA-25 data have been provided by JMA. MERRA data have been provided by NASA through Goddard Earth Sciences Data Information Services Center. The NCEP/NCAR, NCEP/DOE, NCEP-CFSR, and 20CR data are from the Research Data Archive (RDA), which is maintained by CISL at NCAR. Support for this research was provided by The Research Council of Norway under the YGGDRASIL mobility programme, the Russian Foundation for Basic Research under Grants 11-05-01139 and 11-05-00579, by the Grant of the RF President SS-3301.2010.5, by Russian Ministry of Education and Science under contracts 14.740.11.1043 and 11.519.11.5004, and by programs of The Russian Academy of Sciences.

\section{References}

[1] Arctic Climate Impact Assessment, Cambridge University Press, Cambridge, UK, 2005.

[2] S. Solomon, D. Qin, M. Manning et al., Climate Change 2007a: The Physical Science Basis. Contribution of Working Group I to the Fourth Assessment Report of the Intergovernmental Panel on Climate Change, Cambridge University Press, Cambridge, UK, 2007.

[3] M. L. Parry, O. F. Canziani, J. P. Palutikof et al., Climate Change 2007b: Impacts, Adaptation and Vulnerability. Contribution of Working Group II to the Fourth Assessment Report of the Intergovernmental Panel on Climate Change, Cambridge University Press, Cambridge, UK, 2007.

[4] V. P. Meleshko and S. M. Semenov, "Russian Assessment Report on climate change and its impact on the Russian territory," Technical summary, 2008.

[5] M. C. Serreze, J. E. Walsh, F. S. Chapin et al., "Observational evidence of recent change in the northern high-latitude environment," Climatic Change, vol. 46, no. 1-2, pp. 159-207, 2000.

[6] J. Stroeve, M. M. Holland, W. Meier, T. Scambos, and M. Serreze, "Arctic sea ice decline: faster than forecast," Geophysical Research Letters, vol. 34, no. 9, Article ID L09501, 2007.

[7] Y. Liu, J. R. Key, and X. Wang, "Influence of changes in sea ice concentration and cloud cover on recent Arctic surface temperature trends," Geophysical Research Letters, vol. 36, no. 20, Article ID L20710, 2009.

[8] X. Wang and J. R. Key, "Arctic surface, cloud, and radiation properties based on the AVHRR polar pathfinder dataset. Part II: recent trends," Journal of Climate, vol. 18, no. 14, pp. 25752593, 2005.

[9] Y. Liu, J. R. Key, J. A. Francis, and X. Wang, "Possible causes of decreasing cloud cover in the Arctic winter, 1982-2000," Geophysical Research Letters, vol. 34, no. 14, Article ID L14705, 2007.

[10] R. Eastman and S. G. Warren, "Interannual variations of arctic cloud types in relation to sea ice," Journal of Climate, vol. 23, no. 15, pp. 4216-4232, 2010.

[11] V. Ramanathan, R. D. Cess, E. F. Harrison et al., "Cloudradiative forcing and climate: results from the earth radiation budget experiment," Science, vol. 243, no. 4887, pp. 57-63, 1989.
[12] B. A. Wielicki, R. D. Cess, M. D. King, D. A. Randall, and E. F. Harrison, "Mission to Planet Earth: role of clouds and radiation in climate," Bulletin of American Meteorological Society, vol. 76, no. 11, pp. 2125-2154, 1995.

[13] E. F. Harrison, P. Minnis, B. R. Barkstrom, V. Ramanathan, R. D. Cess, and G. G. Gibson, "Seasonal variation of cloud radiative forcing derived from the Earth Radiation Budget Experiment," Journal of Geophysical Research, vol. 95, no. 11, pp. 18687-18703, 1990.

[14] J. M. Intrieri, C. W. Fairall, M. D. Shupe et al., "An annual cycle of Arctic surface cloud forcing at SHEBA," Journal of Geophysical Research C, vol. 107, no. 10, pp. 1-14, 2002.

[15] J. E. Walsh, W. L. Chapman, and D. H. Portis, "Arctic cloud fraction and radiative fluxes in atmospheric reanalyses," Journal of Climate, vol. 22, no. 9, pp. 2316-2334, 2009.

[16] J. A. Curry, W. B. Rossow, D. Randall, and J. L. Schramm, "Overview of arctic cloud and radiation characteristics," Journal of Climate, vol. 9, no. 8, pp. 1731-1764, 1996.

[17] X. Wang and J. R. Key, "Recent trends in arctic surface, cloud, and radiation properties from space," Science, vol. 299, no. 5613, pp. 1725-1728, 2003.

[18] M. D. Shupe and J. M. Intrieri, "Cloud radiative forcing of the Arctic surface: the influence of cloud properties, surface albedo, and solar zenith angle," Journal of Climate, vol. 17, no. 3, pp. 616-628, 2004.

[19] S. Vavrus, "The impact of cloud feedbacks on Arctic climate under Greenhouse forcing," Journal of Climate, vol. 17, no. 3, pp. 603-615, 2004.

[20] Y. Liu, J. R. Key, and X. Wang, "The influence of changes in cloud cover on recent surface temperature trends in the Arctic," Journal of Climate, vol. 21, no. 4, pp. 705-715, 2008.

[21] A. V. Chernokulsky, O. N. Bulygina, and I. I. Mokhov, "Recent variations of cloudiness over Russia from surface daytime observations," Environmental Research Letters, vol. 6, no. 3, Article ID 035202, 2011.

[22] S. Vavrus, D. Waliser, A. Schweiger, and J. Francis, "Simulations of 20th and 21st century Arctic cloud amount in the global climate models assessed in the IPCC AR4," Climate Dynamics, vol. 33, no. 7-8, pp. 1099-1115, 2009.

[23] I. I. Mokhov, A. V. Chernokul'Skii, M. G. Akperov, J. L. Dufresne, and H. Le Treut, "Variations in the characteristics of cyclonic activity and cloudiness in the atmosphere of extratropical latitudes of the Northern Hemisphere based from model calculations compared with the data of the reanalysis and satellite data," Doklady Earth Sciences, vol. 424, no. 1, pp. 147-150, 2009.

[24] D. Lubin and E. Morrow, "Evaluation of an AVHRR cloud detection and classification method over the central arctic ocean," Journal of Applied Meteorology, vol. 37, no. 2, pp. 166177, 1998.

[25] Y. Liu, J. R. Key, R. A. Frey, S. A. Ackerman, and W. P. Menzel, "Nighttime polar cloud detection with MODIS," Remote Sensing of Environment, vol. 92, no. 2, pp. 181-194, 2004.

[26] C. J. Hahn and S. G. Warren, A Gridded Climatology of Clouds over Land (1971-96) and Ocean (1954-97) from Surface Observations Worldwide (NDP-026E), Carbon Dioxide Information Analysis Center, Oak Ridge, Tenn, USA, 2007.

[27] S. G. Warren, R. M. Eastman, and C. J. Hahn, "A survey of changes in cloud cover and cloud types over land from surface observations, 1971-96," Journal of Climate, vol. 20, no. 4, pp. 717-738, 2007. 
[28] N. A. Hughes, "Global cloud climatologies: a historical review," Journal of Climate \& Applied Meteorology, vol. 23, no. 5, pp. 724-751, 1984.

[29] I. I. Mokhov and M. E. Schlesinger, "Analysis of global cloudiness: 1. Comparison of Meteor, Nimbus 7, and International Satellite Cloud Climatology Project (ISCCP) satellite data," Journal of Geophysical Research, vol. 98, no. 7, pp. 1284912868, 1993.

[30] I. I. Mokhov and M. E. Schlesinger, "Analysis of global cloudiness 2. Comparison of ground-based and satellite-based cloud climatologies," Journal of Geophysical Research, vol. 99, no. 8, pp. 17045-17065, 1994.

[31] C. J. Hahn, W. B. Rossow, and S. G. Warren, "ISCCP cloud properties associated with standard cloud types identified in individual surface observations," Journal of Climate, vol. 14, no. 1, pp. 11-28, 2001.

[32] S. M. Thomas, A. K. Heidinger, and M. J. Pavolonis, "Comparison of NOAA's operational AVHRR-derived cloud amount to other satellite-derived cloud climatologies," Journal of Climate, vol. 17, no. 24, pp. 4805-4822, 2004.

[33] A. V. Chernokulsky and I. I. Mokhov, "Intercomparison of global and zonal cloudiness characteristics from different satellite and ground-based data," Earth's Research from Space, vol. 3, pp. 12-29, 2010.

[34] B. C. Weare, "Evaluation of total cloudiness and its variability in the atmospheric model intercomparison project," Journal of Climate, vol. 8, no. 9, pp. 2224-2238, 1995.

[35] A. V. Eliseev, H. Le Treut, I. I. Mokhov, M. Doutriaux-Boucher, and A. V. Chernokulsky, "Validation of TOA radiation and clouds simulated by different versions of the LMD general circulation model in comparison to satellite and ground-based data," Izvestiya, Atmospheric and Ocean Physics, vol. 39, pp. S15-S26, 2003.

[36] M. H. Zhang, W. Y. Lin, S. A. Klein et al., "Comparing clouds and their seasonal variations in 10 atmospheric general circulation models with satellite measurements," Journal of Geophysical Research D, vol. 110, no. 15, pp. 1-18, 2005.

[37] J. A. Griggs and J. L. Bamber, "Assessment of cloud cover characteristics in satelite datasets and reanalysis products for greenland," Journal of Climate, vol. 21, no. 9, pp. 1837-1849, 2008.

[38] A. V. Chernokulsky and I. I. Mokhov, "Comparison of global cloud climatologies," Current Issues of Remote Sensing of Earth from Space, vol. 6, no. 2, pp. 235-243, 2009.

[39] J. Karlsson and G. Svensson, "The simulation of Arctic clouds and their influence on the winter surface temperature in present-day climate in the CMIP3 multi-model dataset," Climate Dynamics, vol. 36, no. 3, pp. 623-635, 2011.

[40] G. M. Stokes and S. E. Schwartz, "The Atmospheric Radiation Measurement (ARM) Program: programmatic background and design of the cloud and radiation test bed," Bulletin of American Meteorological Society, vol. 75, no. 7, pp. 1201-1221, 1994.

[41] D. Randall, J. Curry, D. Battisti et al., "Status of and outlook for large-scale modeling of atmosphere-ice-ocean interactions in the arctic," Bulletin of the American Meteorological Society, vol. 79, no. 2, pp. 197-219, 1998.

[42] J. A. Curry, P. V. Hobbs, M. D. King et al., "FIRE arctic clouds experiment," Bulletin of the American Meteorological Society, vol. 81, no. 1, pp. 5-29, 2000.

[43] T. Uttal, J. A. Curry, M. G. McPhee et al., "Surface heat budget of the arctic ocean," Bulletin of the American Meteorological Society, vol. 83, no. 2, pp. 255-275, 2002.
[44] J. A. Maslanik, J. Key, C. W. Fowler, T. Nguyen, and X. Wang, "Spatial and temporal variability of satellite-derived cloud and surface characteristics during FIRE-ACE," Journal of Geophysical Research D, vol. 106, no. 14, pp. 15233-15249, 2001.

[45] S. Kato, N. G. Loeb, P. Minnis et al., "Seasonal and interannual variations of top-of-atmosphere irradiance and cloud cover over polar regions derived from the CERES data set," Geophysical Research Letters, vol. 33, no. 19, Article ID L19804, 2006.

[46] B. E. Schutz, H. J. Zwally, C. A. Shuman, D. Hancock, and J. P. DiMarzio, "Overview of the ICESat mission," Geophysical Research Letters, vol. 32, no. 21, Article ID L21S01, pp. 1-4, 2005.

[47] D. M. Winker, W. H. Hunt, and M. J. McGill, "Initial performance assessment of CALIOP," Geophysical Research Letters, vol. 34, no. 19, Article ID L19803, 2007.

[48] G. L. Stephens, D. G. Vane, R. J. Boain et al., "The cloudsat mission and the A-Train: a new dimension of space-based observations of clouds and precipitation," Bulletin of the American Meteorological Society, vol. 83, no. 12, pp. 17711742, 2002.

[49] G. G. Mace, Q. Zhang, M. Vaughan et al., "A description of hydrometeor layer occurrence statistics derived from the first year of merged Cloudsat and CALIPSO data," Journal of Geophysical Research D, vol. 114, no. 8, Article ID D00A26, 2009.

[50] J. Key and R. G. Barry, "Cloud cover analysis with Arctic AVHRR data 1. Cloud detection," Journal of Geophysical Research, vol. 94, no. 15, pp. 18521-18535, 1989.

[51] X. Wang and J. R. Key, "Arctic surface, cloud, and radiation properties based on the AVHRR polar pathfinder dataset. Part I: spatial and temporal characteristics," Journal of Climate, vol. 18, no. 14, pp. 2558-2574, 2005.

[52] J. R. Key, The Cloud and Surface Parameter Retrieval (CASPR) System for Polar AVHRR, Cooperative Institute for Meteorological Satellite Studies, University of Wisconsin-Madison, 2002.

[53] B. A. Wielicki, B. R. Barkstrom, E. F. Harrison, R. B. Lee, G. L. Smith, and J. E. Cooper, "Clouds and the earth's radiant energy system (CERES): an earth observing system experiment," Bulletin of the American Meteorological Society, vol. 77, no. 5, pp. 853-868, 1996.

[54] M. D. King, Y. J. Kaufman, W. P. Menzel, and D. Tanre, "Remote sensing of cloud, aerosol, and water vapor properties from the moderate resolution imaging spectrometer (MODIS)," IEEE Transactions on Geoscience and Remote Sensing, vol. 30, no. 1, pp. 2-27, 1992.

[55] P. Minnis, D. Young, S. Sun-Mack, P. W. Heck, D. R. Doelling, and Q. Z. Trepte, "CERES cloud property retrievals from imagers on TRMM, Terra, and Aqua," in Proceedings of the Remote Sensing of Clouds and the Atmosphere VIII, vol. 5235 of Proceedings of SPIE, pp. 37-48, Barcelona, Spain, September 2003.

[56] R. A. Schiffer and W. B. Rossow, "The International Satellite Cloud Climatology Project (ISCCP): the first project of the World Climate Research Programme," Bulletin of American Meteorological Society, vol. 64, no. 7, pp. 779-784, 1983.

[57] W. B. Rossow and L. C. Garder, "Cloud detection using satellite measurements of infrared and visible radiances for ISCCP," Journal of Climate, vol. 6, no. 12, pp. 2341-2369, 1993. 
[58] W. B. Rossow and R. A. Schiffer, "Advances in understanding clouds from ISCCP," Bulletin of the American Meteorological Society, vol. 80, no. 11, pp. 2261-2287, 1999.

[59] S. A. Ackerman, K. I. Strabala, W. P. Menzel, R. A. Frey, C. C. Moeller, and L. E. Gumley, "Discriminating clear sky from clouds with MODIS," Journal of Geophysical Research D, vol. 103, no. 24, pp. 32141-32157, 1998.

[60] R. A. Frey, S. A. Ackerman, Y. Liu et al., "Cloud detection with MODIS. Part I: improvements in the MODIS cloud mask for Collection 5," Journal of Atmospheric and Oceanic Technology, vol. 25, no. 7, pp. 1057-1072, 2008.

[61] S. A. Ackerman, R. E. Holz, R. Frey, E. W. Eloranta, B. C. Maddux, and M. McGill, "Cloud detection with MODIS. Part II: validation," Journal of Atmospheric and Oceanic Technology, vol. 25, no. 7, pp. 1073-1086, 2008.

[62] A. K. Heidinger, M. J. Foster, and A. T. Evan, "A naive bayesian cloud detection scheme derived from CALIPSO and applied within PATMOS-x," Journal of Applied Meteorology and Climatology. In press.

[63] A. K. Heidinger, CLAVR-x Cloud Mask Algorithm Theoretical Basis Document (ATBD), NOAA/NESDIS/Office of Research and Applications, Washington, DC, USA, 2004.

[64] C. J. Hahn and S. G. Warren, Extended Edited Synoptic Cloud Reports from Ships and Land Stations Over the Globe, 19521996. NDP-026C, CDIAC, Oak Ridge, Tenn, USA, 1999.

[65] C. J. Hahn, S. G. Warren, and J. London, "The effect of moonlight on observation of cloud cover at night, and application to cloud climatology," Journal of Climate, vol. 8, no. 5, pp. 1429-1446, 1995.

[66] R. Kistler, E. Kalnay, W. Collins et al., "The NCEP-NCAR 50year reanalysis: monthly means CD-ROM and documentation," Bulletin of the American Meteorological Society, vol. 82, no. 2, pp. 247-267, 2001.

[67] S. M. Uppala, P. W. Kållberg, A. J. Simmons et al., "The ERA40 re-analysis," Quarterly Journal of the Royal Meteorological Society, vol. 131, no. 612, pp. 2961-3012, 2005.

[68] D. P. Dee, S. M. Uppala, A. J. Simmons et al., "The ERAInterim reanalysis: configuration and performance of the data assimilation system," Quarterly Journal of the Royal Meteorological Society, vol. 137, no. 656, pp. 553-597, 2011.

[69] S. Saha, S. Moorthi, H. L. Pan et al., "The NCEP climate forecast system reanalysis," Bulletin of the American Meteorological Society, vol. 91, no. 8, pp. 1015-1057, 2010.

[70] G. P. Compo, J. S. Whitaker, P. D. Sardeshmukh et al., "The twentieth century reanalysis project," Quarterly Journal of the Royal Meteorological Society, vol. 137, no. 654, pp. 1-28, 2011.

[71] K. A. Campana, Y.-T. Hou, K. E. Mitchell et al., "Improved diagnostic cloud parameterization in NMC's global model," in Proceedings of the 10th Conference on Numerical Weather Prediction, pp. 324-325, Portland, Ore, USA, 1994.

[72] M. Kanamitsu, W. Ebisuzaki, J. Woollen et al., "NCEPDOE AMIP-II reanalysis (R-2)," Bulletin of the American Meteorological Society, vol. 83, no. 11, pp. 1631-1559, 2002.

[73] K. M. Xu and D. A. Randall, "Evaluation of statistically based cloudiness parameterizations used in climate models," Journal of the Atmospheric Sciences, vol. 53, no. 21, pp. 3103-3119, 1996.

[74] K. Onogi, J. Tsutsui, H. Koide et al., “The JRA-25 reanalysis," Journal of the Meteorological Society of Japan, vol. 85, no. 3, pp. 369-432, 2007.

[75] S. Moorthi, H.-L. Pan, and P. Caplan, "Changes to the 2001 NCEP operational MRF/AVN global analysis/forecast system," NWS Technical Procedures Bulletin, vol. 484, 14 pages, 2001.
[76] M. M. Rienecker, M. J. Suarez, R. Gelaro et al., "MERRA: NASA's modern-era retrospective analysis for research and applications," Journal of Climate, vol. 24, no. 14, pp. 36243648, 2011.

[77] M. Tiedtke, "Representation of clouds in large-scale models," Monthly Weather Review, vol. 121, no. 11, pp. 3040-3061, 1993.

[78] J. T. Bacmeister, M. J. Suarez, and F. R. Robertson, "Rain reevaporation, boundary layer-convection interactions, and pacific rainfall patterns in an AGCM," Journal of the Atmospheric Sciences, vol. 63, no. 12, pp. 3383-3403, 2006.

[79] Y. Liu, S. A. Ackerman, B. C. Maddux, J. R. Key, and R. A. Frey, "Errors in cloud detection over the arctic using a satellite imager and implications for observing feedback mechanisms," Journal of Climate, vol. 23, no. 7, pp. 1894-1907, 2010.

[80] A. J. Schweiger, R. W. Lindsay, J. R. Key, and J. A. Francis, "Arctic clouds in multiyear satellite data sets," Geophysical Research Letters, vol. 26, no. 13, Article ID 1999GL900479, pp. 1845-1848, 1999.

[81] K. E. Taylor, "Summarizing multiple aspects of model performance in a single diagram," Journal of Geophysical Research D, vol. 106, no. 7, pp. 7183-7192, 2001.

[82] D. Wylie, "Diurnal cycles of clouds and how they affect polarorbiting satellite date," Journal of Climate, vol. 21, no. 16, pp. 3989-3996, 2008.

[83] Y. Liu, J. R. Key, A. Schweiger, and J. Francis, "Characteristics of satellite-derived clear-sky atmospheric temperature inversion strength in the Arctic, 1980-96," Journal of Climate, vol. 19, no. 19, pp. 4902-4913, 2006.

[84] A. Devasthale, U. Willén, K. G. Karlsson, and C. G. Jones, "Quantifying the clear-sky temperature inversion frequency and strength over the Arctic Ocean during summer and winter seasons from AIRS profiles," Atmospheric Chemistry and Physics, vol. 10, no. 12, pp. 5565-5572, 2010.

[85] S. P. Palm, S. T. Strey, J. Spinhirne, and T. Markus, "Influence of Arctic sea ice extent on polar cloud fraction and vertical structure and implications for regional climate," Journal of Geophysical Research D, vol. 115, no. 21, Article ID D21209, 2010.

[86] E. W. Eloranta, J. P. Garcia, I. A. Razenkov et al., "Cloud fraction statistics derived from2-years of high spectral resolution lidar data acquired at Eureka, Canada," in Proceedings of the 24th International Laser Radar Conference, vol. 555-558, Boulder, Colo, USA, 2008. 

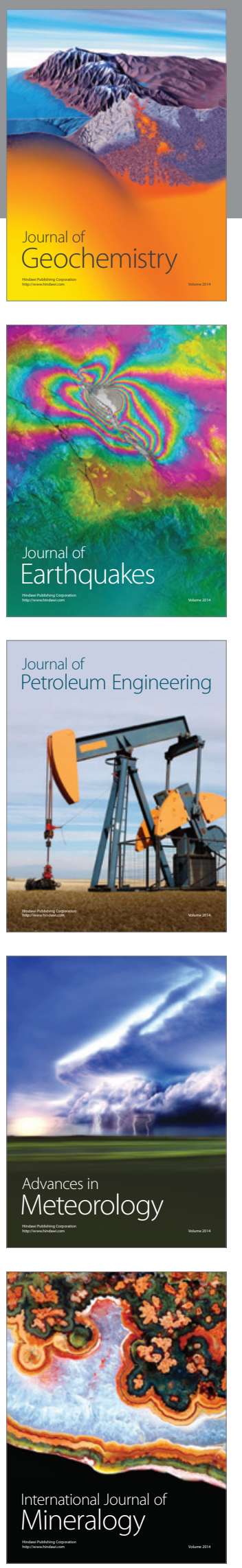
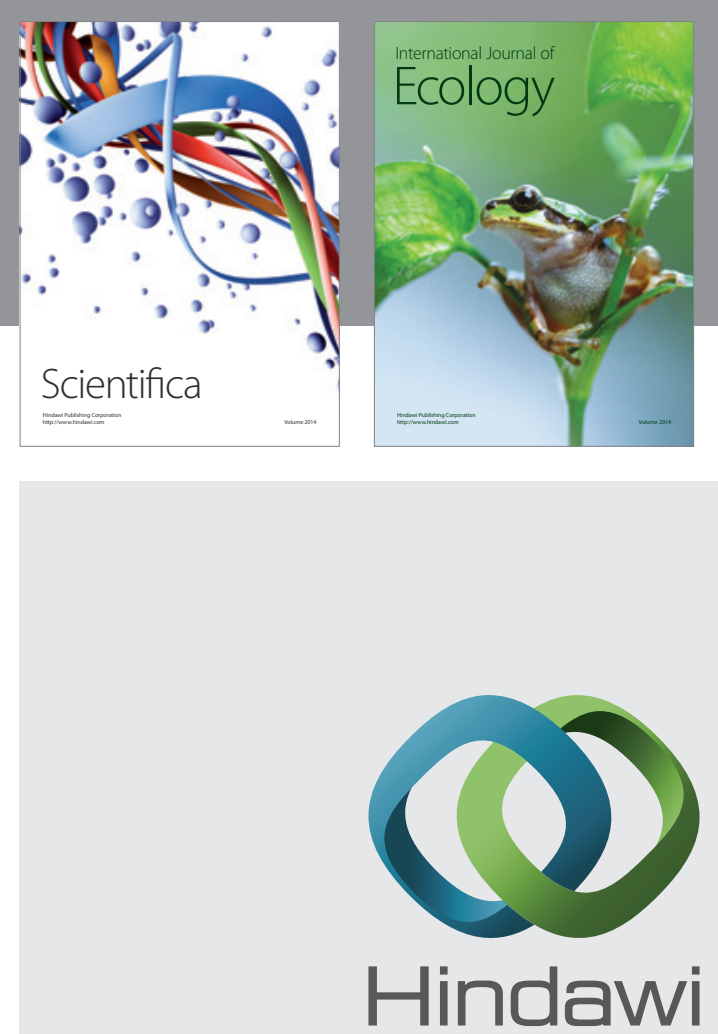

Submit your manuscripts at http://www.hindawi.com
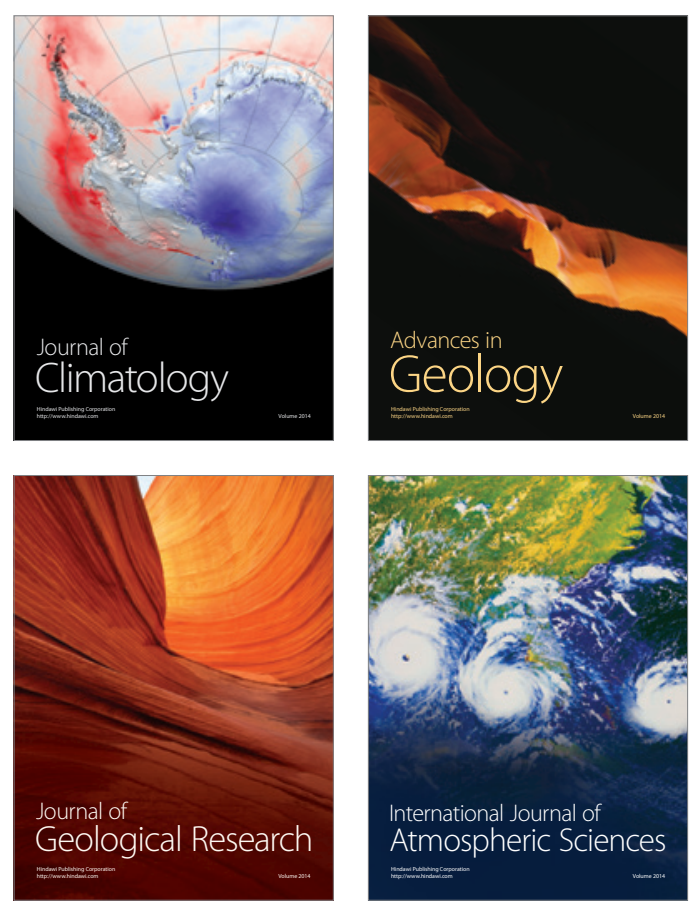
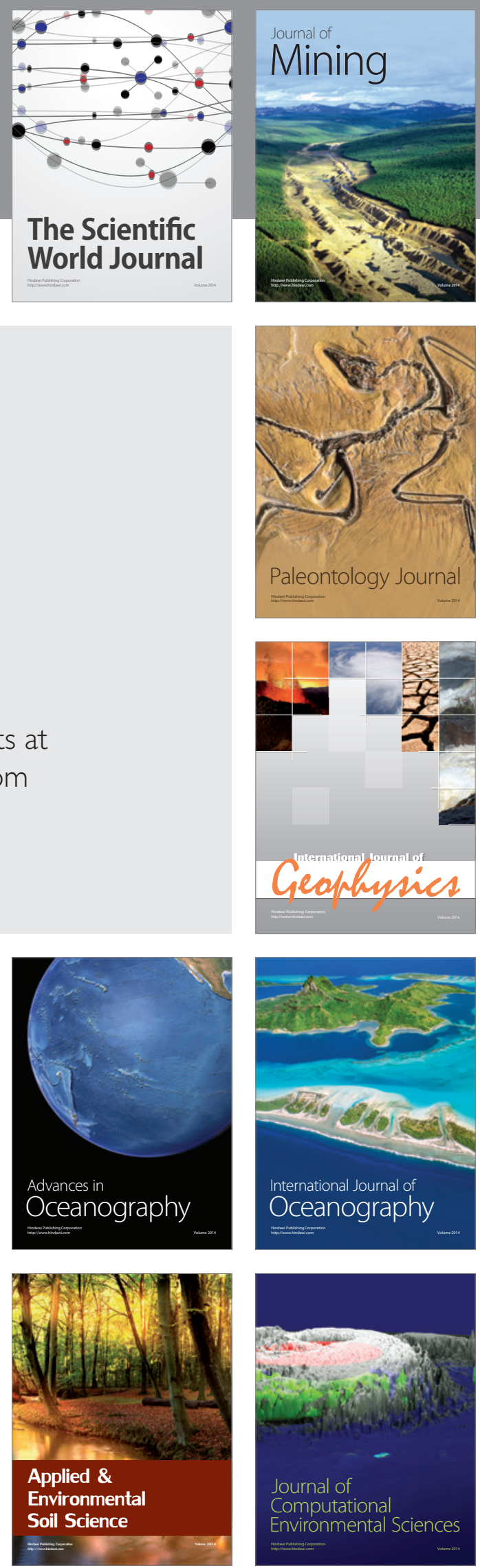